\title{
Vehicular Traffic Noise Modelling of Urban Area- A Contouring \& Artificial Neural Network-Based Approach
}

Abhijit Debnath ( $\sim$ abhijit1732@gmail.com )

Indian Institute of Technology BHU Varanasi https://orcid.org/0000-0002-4783-5174

Prasoon Kumar Singh

IIT (ISM): Indian Institute of Technology

Sushmita Banerjee

Sharda University

\section{Research Article}

Keywords: traffic noise, traffic flow, noise descriptors, indexes, contour, ANN

Posted Date: November 15th, 2021

DOI: https://doi.org/10.21203/rs.3.rs-707329/v1

License: (c) (i) This work is licensed under a Creative Commons Attribution 4.0 International License.

Read Full License

Version of Record: A version of this preprint was published at Environmental Science and Pollution Research on February 3rd, 2022. See the published version at https://doi.org/10.1007/s11356-02117577-1. 
Approach

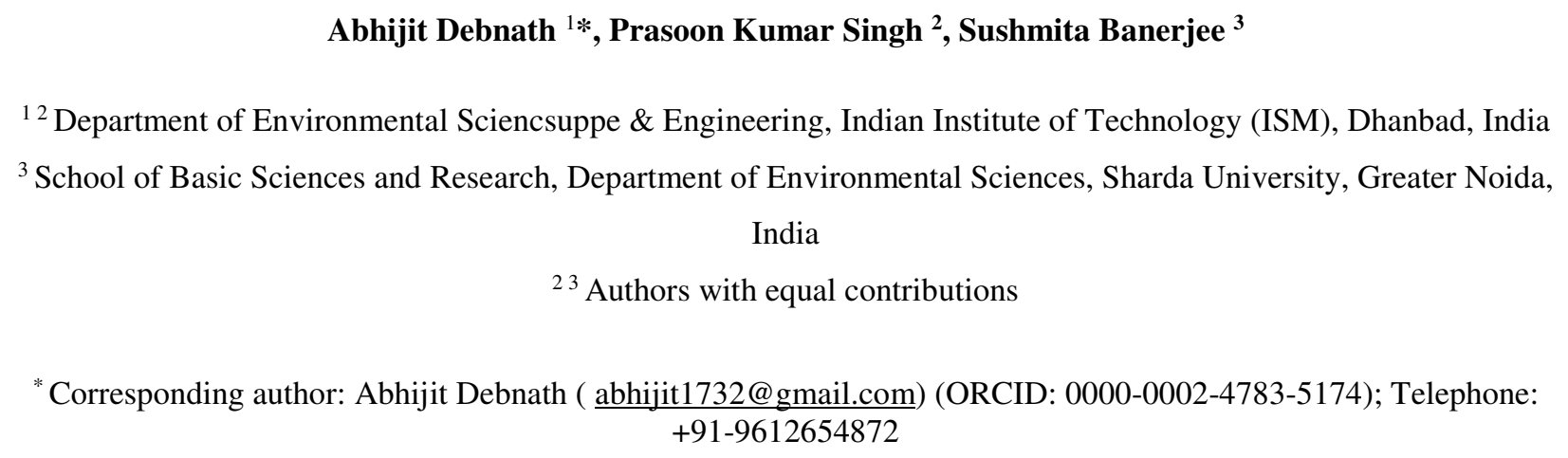

${ }^{23}$ Authors with equal contributions

${ }^{*}$ Corresponding author: Abhijit Debnath ( abhijit1732@ gmail.com) (ORCID: 0000-0002-4783-5174); Telephone: $+91-9612654872$

Abstract: Road traffic vehicular noise is one of the main sources of environmental pollution in urban areas of India. Also, steadily increasing urbanization, industrialization, infrastructures around city condition causing health risks among the urban populations. In this study we have explored noise descriptors ( $\mathrm{L}_{10}, \mathrm{~L}_{90}, \mathrm{~L}_{\mathrm{dn}}$, LNI, TNI, NC), contour plotting and finds the suitability of artificial neural networks (ANN) for the prediction of traffic noise all around the Dhanbad township in 15 monitoring stations. In order to develop the prediction model, measuring noise levels of five different hours, speed of vehicles and traffic volume in every monitoring point have been studied and analyzed. Traffic volume, percent of heavy vehicles, Speed, traffic flow, road gradient, pavement, road side carriageway distance factors taken as input parameter, whereas $\mathrm{L}_{\mathrm{Aeq}}$ as output parameter for formation of neural network architecture. As traffic flow is heterogenous which mainly contains 59\% 2-wheelers and different vehicle specifications with varying speeds also effects driving and honking behavior which constantly changing noise characteristics. From radial noise diagrams shown that average noise levels of all the stations beyond permissible limit and highest noise levels were found at the speed of 50-55 km/h in both peak and non-peak hours. Noise descriptors clearly indicates high annoyance level in the study area. Artificial neural network with 7-7-5 formation has been developed and found as optimum due to its sum of square and overall relative error $0.858 \& .029$ in training and $0.458 \& 0.862$ in testing phase respectively. Comparative analysis between observed and predicted noise level shows very less deviation up to $\pm 0.6 \mathrm{~dB}(\mathrm{~A})$ and the $\mathrm{R}^{2}$ linear values are more than 0.9 in all five noise hours indicating the accuracy of model. Also, it can be concluded that ANN approach is much superior in prediction of traffic noise level to any other statistical method.

Keywords: traffic noise; traffic flow; noise descriptors; indexes; contour; ANN

\footnotetext{
${ }^{1}$ Present Address: Department of Civil Engineering, Indian Institute of Technology (BHU), Varanasi, India
} 
1. Traffic noise level of all over the Dhanbad township area are beyond permissible limit in peak and non-peak hours.

2. Study explores the contour noise plots w.r.t speed and volume, noise descriptors, finds suitability of ANN modelling.

3. Noise descriptors indicates high annoyance level, a high degree of variation in traffic flow.

4. ANN model shows deviation up to $\pm 0.6 \mathrm{~dB}$ (A) compared to measured levels and $\mathrm{R}^{2}$ linear values (goodness of fit) are nearby best fit. 


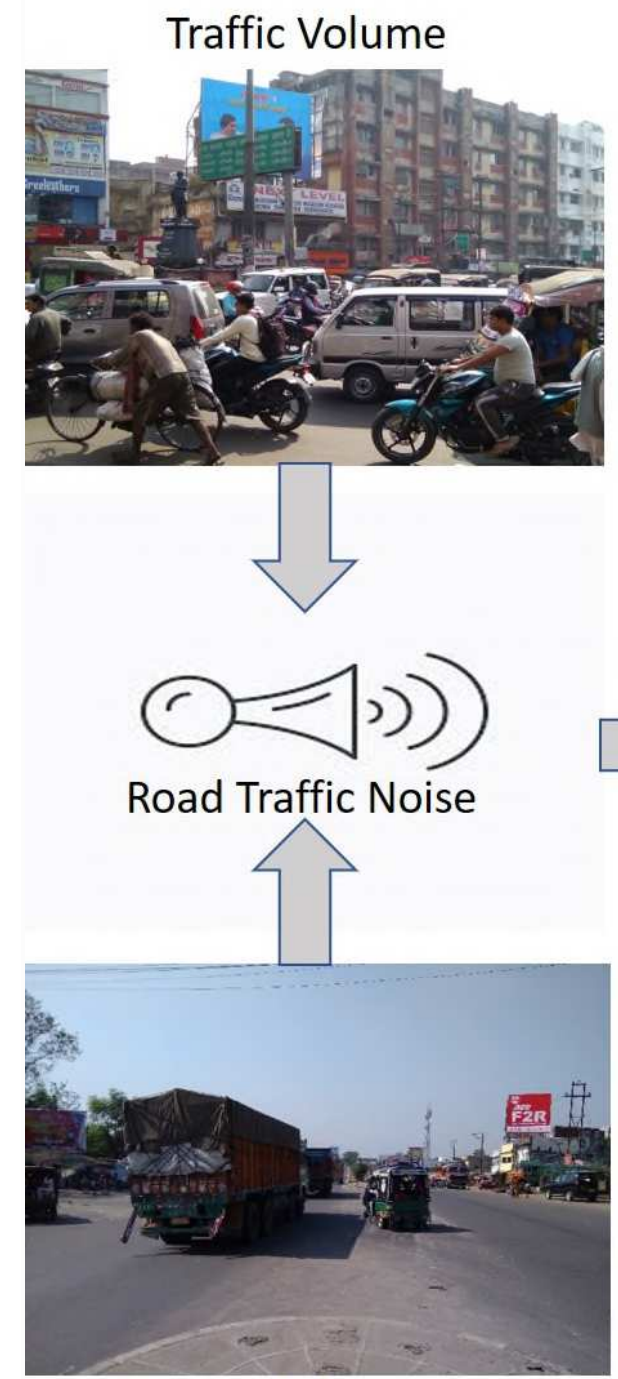

Traffic Volume

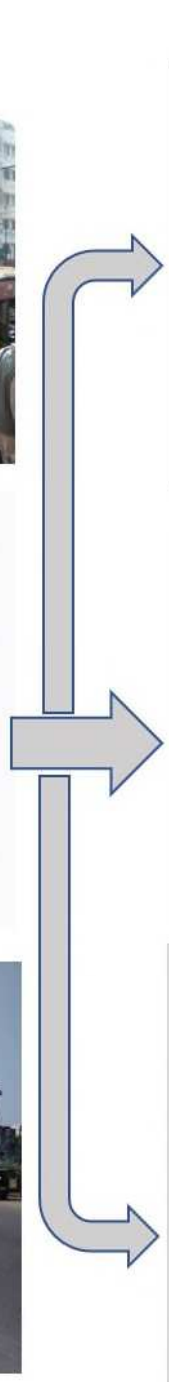

41
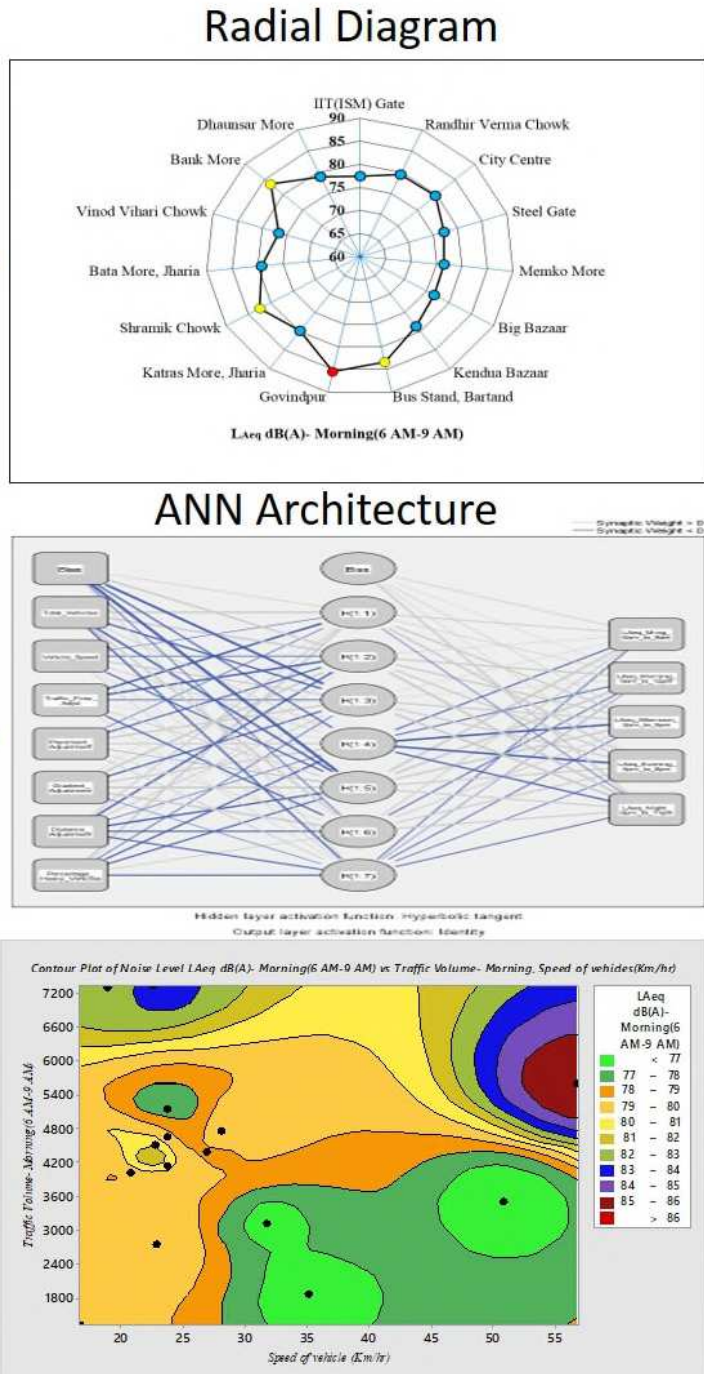

Contour Plot

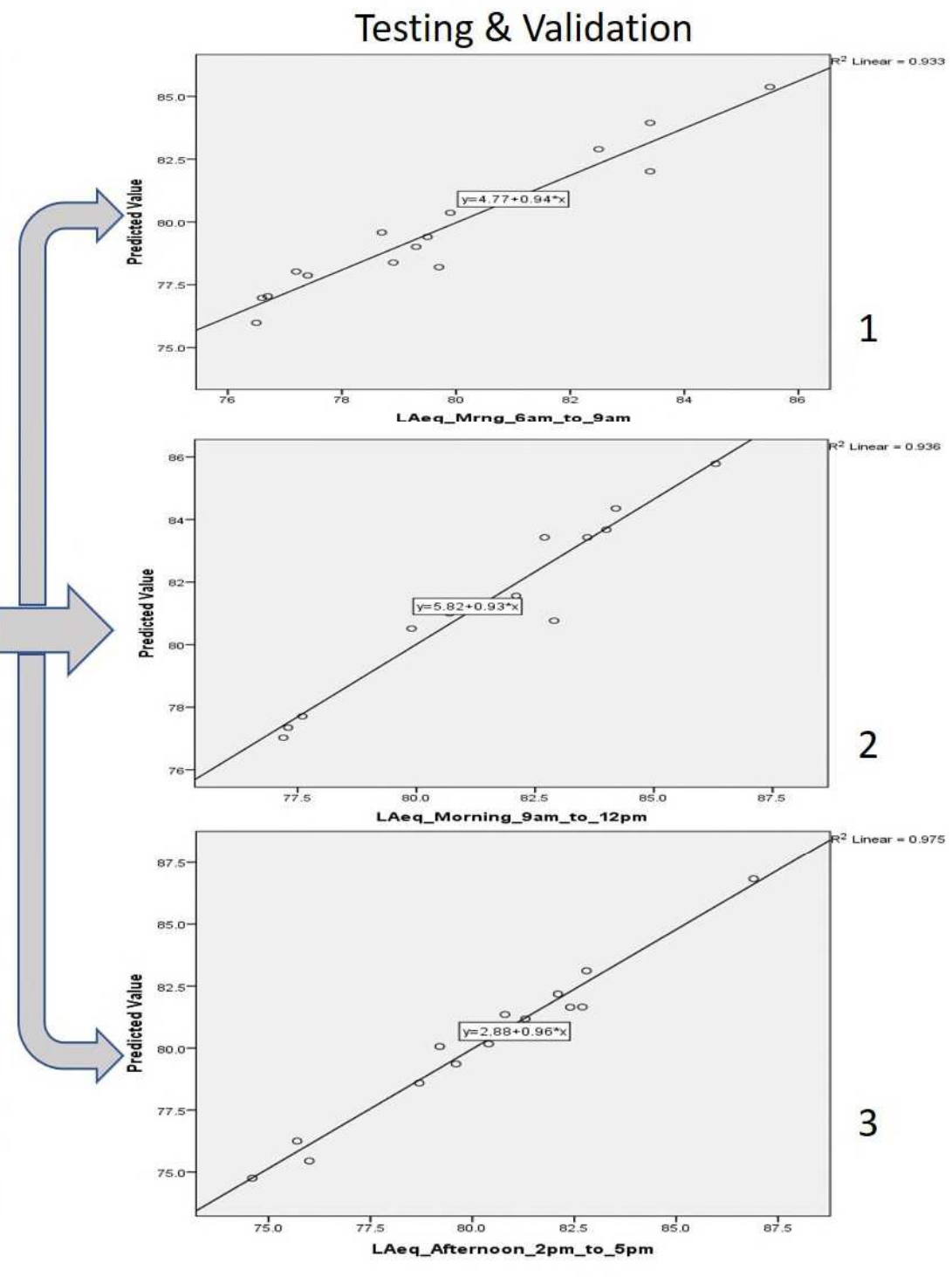




\subsection{Introduction}

Noise pollution is one of the major issues in urban environments which arises due to steady increase of vehicular traffic in roads, urbanization, industrialization, and infrastructures around city conditions. Transportation systems are an important feature of many developed societies, as transportation systems deliver the essential infrastructure to ensure movement and convenience for societal needs (Di et al. 2018). The world is experiencing an exponential rise in number of vehicles, leading to an rise in the traffic noise levels (Nedic et al. 2014) and these levels results many health deprivation in residential and commercial areas such as sleep problems, headaches, irritation, unusual tiredness (Huang et al. 2017). In Indian conditions, traffic noise mainly occurs due to unnecessary horns as well as interaction between vehicle tires and road surface, engine noise etc. (Konbattulwar et al. 2016). Vehicle horns are continuously honking in the road network system due to lack of proper traffic management, high volume of vehicles, driver discipline and high commute in the road (Konbattulwar et al. 2016; Laxmi et al. 2019). Indian roads cater, all types of vehicles including two, three, or four-wheelers and also heavy vehicles like buses, trucks, trailers, tractors. Due to mixed traffic flow with variable speeds and vehicle characteristics, maintaining lane discipline is even more challenging. In Indian condition where heterogeneity in traffic predominates due to presence of all types of vehicles, size of roads, tyre-pavement interactions, operating characteristics such as vehicle speed, driving and honking behavior regularly effects road traffic noise characteristics (Kalaiselvi and Ramachandraiah 2016; Vijay et al. 2018).

Many Governments of developing countries across the globe prefer to overlook the negative consequences of noise pollution in comparison to other forms of pollution in the environment, such as water, land, or air pollution (Hamad et al. 2017). Noise exposure to humans is potentially hazardous and can cause psychological stress or nonauditory effects and auditory effects (Pathak et al. 2008; Agarwal and Swami 2010; Praticò 2014). Different effects of traffic noise in human being can be classified as (a) Subjective effect e.g. annoyance (Licitra et al. 2016; Minichilli et al. 2018), disturbance etc. (b) Behavioral effect like interference with sleep, speak or any general task (Basner and McGuire 2018) (c) Physiological effects which causes frightened phenomenon, resulting harmful effect in body such as extremely exposure may cause deafens (Banerjee et al. 2008a; Marathe 2012; Paschalidou et al. 2019) and (d) effects on work performance which results reduction of work productivity (Vukić et al. 2021) and misunderstandings. Further, chronic exposure to noise levels can lead to other severe impacts on public health like CVD's, metabolic disorders, and other psychological effects (Dzhambov et al. 2017; Gilani and Mir 2021a). Hearing loss as a result of excessive noise exposure is referred to as auditory effects. The major auditory consequences are acoustic trauma, tinnitus, transient hearing loss, and permanent hearing loss. Though permanent hearing loss is a cumulative process, it has several characteristics such as continuous exposure of high frequency noise $(4000 \mathrm{~Hz})$, exposure time etc. Muzet (2007) emphasized the importance of sleep as a component in environmental health and its sensitivity to ambient noise processed by sleeper sensory systems. According to De leon et al. (2020), noise levels above 65 dBA can cause a variety of problems, including sleep disturbances (Muzet 2007), learning impairments (Zacarías et al. 2013), cardiovascular (Babisch et al. 2005), hypertension, and ischemic heart disease (Dratva et al. 2012), diastolic blood pressure (Petri et al. 2021) etc. Miedema and Oudshoorn (2001) created a normal distribution-based noise annoyance 
aircraft, road traffic, and railways. The scale distributions are: highly annoyed (72), annoyed (50), a little annoyed (28). Babisch et al. (2005) conducted a hospital-based hypothesis research that confirmed the well-known fact that prolonged high-level noise exposure can induce cardiovascular diseases and, over time, increase the risk of myocardial infarction. Dratva et al. (2012) studied the effects of railway noise on human blood pressure and observed that it had a negative effect. Licitra et al. (2016) conducted interviews with residents to assess the effects of railway noise and vibrations in Pisa, Italy's surrounding urban areas. They found a higher degree of irritation among citizens, which is supported by the dose-effect relationship curve. In the same Pisa inhabitants aged 37 to 72 years old, Petri et al. (2021) discovered that night time train, airport, and road noise levels induce hypertension and increased diastolic blood pressure. Rossi et al. (2018) investigated the effects of background noise (LFN: low frequency noise) in indoor circumstances with target exposure as people aged 19 to 29 years old (Erickson and Newman 2017). Vukic et al. (2021) investigated the impact of noise exposure on aboard seafarers, as well as their perceptions of noise reduction measures. It should be noted that small remedial actions, such as slight decreases in traffic noise levels, may not always be adequate to minimize noise discomfort and common mental disorders, as well as to create noticeable improvements in quality of life.

Noise pollution levels usually expressed as $\mathrm{L}_{\mathrm{Aeq}} \mathrm{dB}(\mathrm{A})$. Noise levels such as L10, L90, Ldn, Noise Pollution Level (LNP), Traffic Noise Index (TNI), and Noise Climate (NC) in $\mathrm{dB}(\mathrm{A})$ were established to assess the intensity of traffic noise and its effects on the environment (Di et al. 2018). Several studies also conducted to analyze the traffic noise induced annoyance level in road side populated areas (Gilani and Mir 2021b). The subjective, behavioral and physiological effects also depends on the energy based acoustic exposure indexes and descriptors (Wunderli et al. 2016; Bahadure and Kotharkar 2018; Basner and McGuire 2018). These indexes are useful to analyze the level of discomfort, as well as the physiological and psychological effects of traffic noise among populated urban areas. Different types of generic algorithms (Brown and De Coensel 2018) and procedures (Wunderli et al. 2016) also explored for detection of individual noise events above a particular threshold level, which is arising due to road traffic based on above mentioned percentage and average noise levels. The extent of noise pollution may be represented using a noise map, which can be used to assess environmental consequences and guide local and global action strategies (Klæboe et al. 2006; Zannin et al. 2013; Bastián-Monarca et al. 2016; Di et al. 2018). Noise map represents a cartographic representation of that area which looks like as hotspot or cooler (Manojkumar et al. 2019). Debnath and Singh (2018) depicted the 2D contour noise maps of Dhanbad area and predicted the road traffic noise levels with CRTN regression modelling (Debnath and Singh 2018).

Engine noise, honking, flow composition, and vehicle speed are all variables that impact road traffic noise emissions, but the interaction between the vehicle tyre and the road surface is another key component that has been studied by numerous researches. Pratico (2014) and Bianco et al. (2020) discussed the multitude of acoustic parameters are influenced by the three major dominions (generation, absorption, and propagation) that impact pavement acoustic performance. The generation of tyre/road noise depends on two factors such as aerodynamic and vibro-dynamic phenomenon. Several researchers investigated the noise produced by tyre-pavement interaction and created techniques to assess the interaction between a vehicle tyre and the pavement. According to Sandberg and Ejsmont (2002) tyre 
road noise is a complicated phenomenon that arises from a mix of airborne (air trapped in tyre tread as it rolls along the pavement, frequencies greater than $1 \mathrm{kHz}$ ) and structure-borne events, caused by interaction between vehicle tyre and pavement (Praticò and Anfosso-Lédée 2012). Mechanical vibrations also generated during the successive interaction of tyre and pavement surface (Praticò et al. 2021). Bianco et al. (2020) also looked at previous and contemporary vibro dynamic mechanisms, such as stick-and-slip (tyre tread motion relative to road surface) and stickand-snap (presently newly laid pavements where strong grip on tyre). Boodihal et al. (2014) established a methodology to assess noise emissions from tyre-road interactions in three types of concrete roads in Bangalore (conventional asphalt, Portland cement concrete, and plastic modified asphalt concrete. Highest noise level received in the interaction with conventional asphalt road than the plastic modified asphalt concrete, Portland cement concrete. Khan and Biligiri (2018) used statistical pass-by (SPB) and Close Proximity (CPX) methods to study two distinct concrete surfaces in IIT Kharagpur, India, and found that cement concrete surfaces produce higher noise levels than asphalt concrete surfaces. Furthermore, comparing the SPB and CPX method measuring methodologies, there is a $5 \mathrm{~dB}(\mathrm{~A})$ difference in cement concrete and a $10 \mathrm{~dB}(\mathrm{~A})$ difference in asphalt concrete. Del Pizzo et al. (2020) studied the acoustic performance of various rubberized pavements by experimentally conducting the interaction between tyre noise and road texture through CPX measurements. In addition, De Leon et al. (2020) compared the acoustic performance of rubberised and conventional road surfaces, finding that rubberised asphalt surfaces had a better noise reduction potential than traditional surfaces. According to many researchers, the use of low noise road surfaces are the optimum solution for noise emission from tyre-pavement interaction (Praticò 2014; Licitra et al. 2017; Del Pizzo et al. 2020; Teti et al. 2020; Praticò et al. 2021). Licitra et al. (2017) used different tread pattern tyre to evaluate noise emission by CPX method in low-noise road surfaces to achieve effective mitigation. Teti et al. (2020) studied the modelling of two different CPX broadband levels in newly laid road surfaces and predicted satisfactory acoustic performance in case of first model with low and high frequency contributions than the second model which shows lower RMSE.

Noise prediction models for road traffic are widely used to forecast noise levels (Di et al. 2018). Among the used models United Kingdom (UK), India, Ireland, Hong Kong, Australia, and New Zealand mainly using UK's Calculation of Road Traffic Noise (CoRTN) model (Givargis and Mahmoodi 2008; Manojkumar et al. 2019; Peng et al. 2019) whereas US Follows the Federal Highway Administration (FHWA), Stamina and TNM models (FHWA Traffic Noise Model 1998; Golmohammadi et al. 2009; Jha and Kang 2009; Pathak et al. 2018). Several other models like RLS 90 (Germany), STL-86 (Switzerland), ASJ-1993 (Japan) followed by different countries (Acoustical Society of Japan 1999; Steele 2001; Quartieri et al. 2009; Sharma et al. 2014; Kalaiselvi and Ramachandraiah 2016; Thakre et al. 2020). Despite the fact that various road traffic noise models are used, the input parameters included in these models vary depending on their local meteorological condition, traffic volume, traffic composition, vehicle speed, percentage of heavy vehicles, and road impacts in that situation while sound propagation methods of maximum models are energy based (Konbattulwar et al. 2016; Hamad et al. 2017). Another study was carried out on the development of a road traffic simulation model for predicting instantaneous sound levels of different vehicle categories, as well as the calculation of percentile levels in a specific noise event (De Coensel et al. 2016). A transitional dynamics-based six-category heavy vehicle noise emission model has been developed in New South Wales, Australia, to forecast the noise levels generated by a mix fleet of heavy trucks. (Peng et al. 2019). The factors of this model are vehicle speed, 
acceleration, weight, aerodynamic properties, road grade acting as its factors. In Europe, a dynamic traffic noise tool has been developed by integrating microscopic traffic simulation software with the CNOSSOS-EU noise emission model to forecast the noise level of both internal combustion engines and electric cars at various traffic flows (EstévezMauriz and Forssén 2018). In order to study the dynamic changes of noise levels, CNOSSOS-EU has been applied for roundabout and signalized intersections. Maximum models mainly developed by the above literatures deals with either heavy vehicles or an individual vehicles categories or percentile levels or dynamics of vehicles. Only a few researches have been explored covering all aspects of noise modelling in terms of vehicle categories, speed, volume, heavy vehicles, road characteristics, distance effects, etc. Many researchers also developed noise prediction models with the use of soft computing techniques as Artificial Neural Network (ANN) (Cammarata et al. 1995), time series models including autoregressive models (ARIMA) (Hamed et al. 1995), deep learners ( $\mathrm{Lv}$ et al. 2015), tensor completion (Tan et al. 2016), pattern discovery (Habtemichael and Cetin 2016), space-temporal correlations (Cai et al. 2016), Bayesian approach (Wang et al. 2014) and graph-theoretic approaches (Gilani and Mir 2021c) to cater road conditions in the respective countries which establishes relation between variables with fairly good results. ANNs are used extensively in the fields ranging from finance to medicine, engineering and science due to accurate predictivity and definite relationship between dependent and independent variables unless it found to be more complex with traditional techniques of correlations and group differences (Givargis and Karimi 2010). Application of these models help to undertake several mitigation measures for reduction traffic noise in road condition (Ramírez and Domínguez 2013). Recent days studies also carried out to enhance the prediction efficiencies of vehicular noise modelling, by developing emotional artificial neural net network (EANN) and applying over classical feed forward neural network (FFNN) structure which showed a 9-14 percent improvement over FFNN (Nourani et al. 2020). Similarly, ANN based traffic noise modelling for mountainous city roads have been developed from modifying HJ 2.4-2009 noise model and validated in the hilly city, Chongqing of China (Chen et al. 2020). Neural networks out-perform the regression modelling to predict the $\mathrm{L}_{\mathrm{Aeq}}$ and $\mathrm{L}_{10}$ for a noise event (Garg et al. 2015). In case of prediction of noise emitted from a electric vehicle passing on single lane at a constant speed, it is observed than artificial neural network model has higher correlation than of linear regression model (Steinbach and Altinsoy 2019). From above discussion it is clear that neural networks perform better than regression models for noise prediction. Multilayer Artificial Neural network model has been applied in this study, for prediction of traffic noise in Indian conditions in a statistically sound manner.

This paper mainly constitutes four sections of study. First section contains general information of all monitoring stations, road networks, methodology flowsheet, traffic noise models and input variables for neural network. The overall data sets of total nos. of vehicles, noise level descriptors and indexes has been presented in the middle section. Third section reflects the radial figures of average noise level ( $\mathrm{L}_{\text {Aeq }}$ ) of all monitoring stations. We have also developed contour noise plots to find out at what condition noise level of that monitoring station has been increased. Then development of neural network modelling with model evaluation, results and discussion is also presented in this section. Finally, the conclusion is presented in fourth section. 


\subsection{Study Area}

190

Dhanbad is one of the major coal cities of India. We have selected 15 monitoring points of the Dhanbad city

191 to assess noise pollution and the counting of different types of vehicles in this study. Monitoring points are selected

192 according to major road intersections, junction points, bus stations, markets among the township area, where traffic is

193 always high during peak timing of the day and night hours. Fig. 1 gives the view of road map of Dhanbad township

194 area with monitoring locations. In Fig. 2 shows point source, point receiver and settlements locations of the monitoring

195 stations (Debnath and Singh, 2018).The yellow coding indicates point source, green coding indicates the point receiver

196 and red coding indicates settlements. Noise data collection based on the site selection criteria mentioned in Table 1.

197

198

199

200

201

202

203

204

205

206

207

208

209

210

211

212

213

214

215

216

217

218 


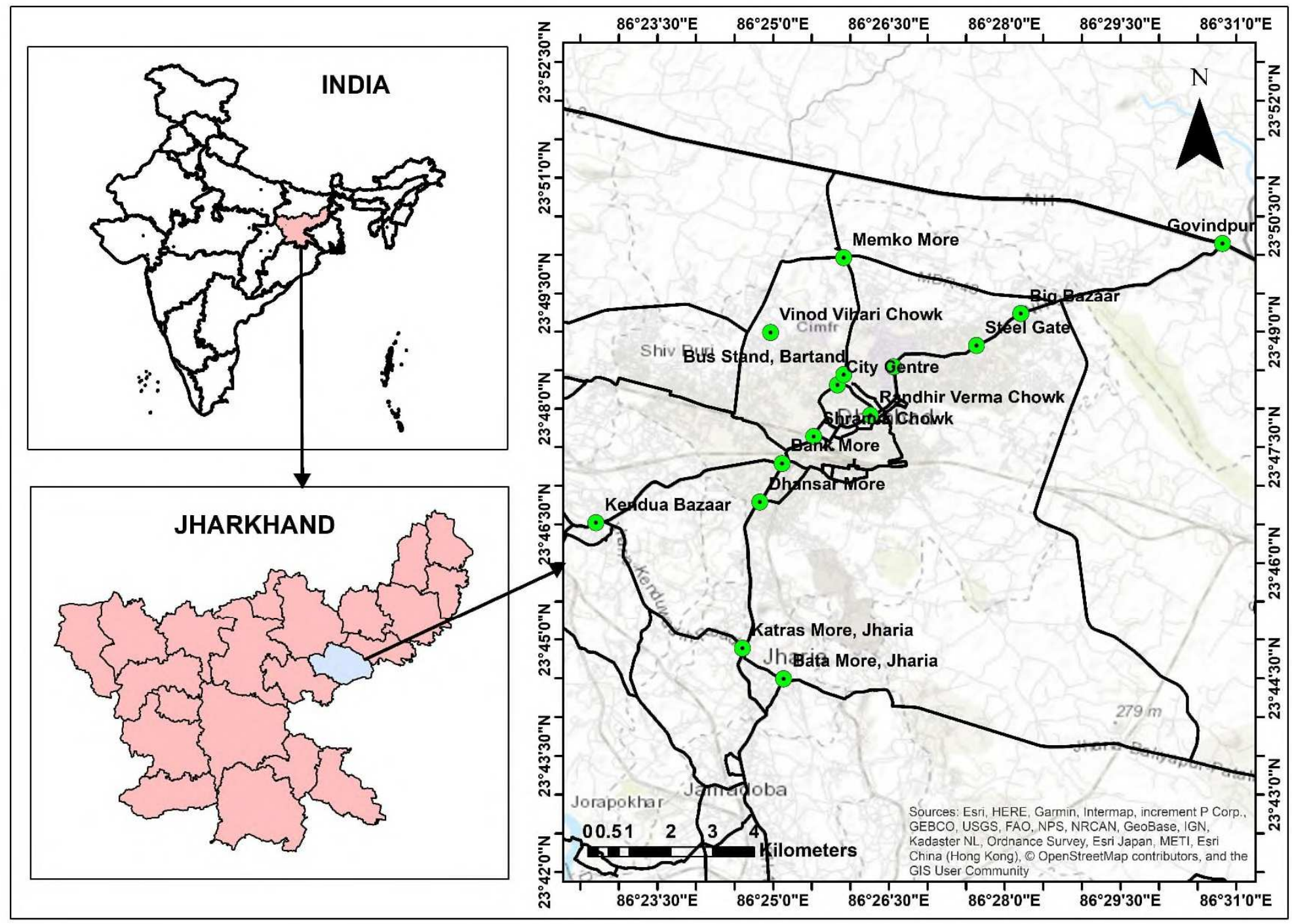




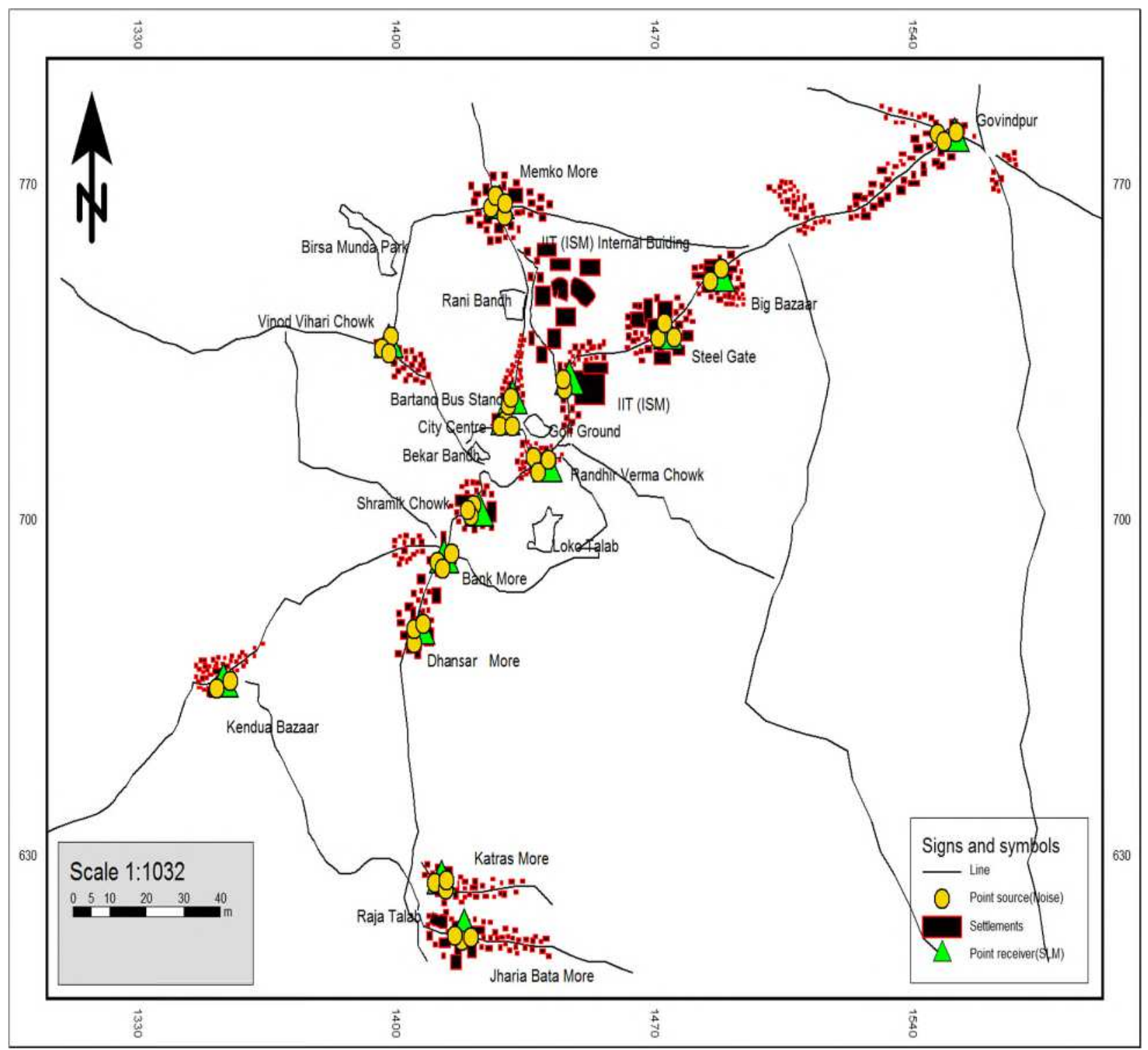

Fig. 2 Point source, Point receiver and Settlements locations of the monitoring stations

224 Table 1 Description of traffic noise monitoring sites in Dhanbad City, Jharkhand

Monitoring

Station

IIT(ISM) Gate

\section{Description}


City Centre It is one of the population hub of the city where three road intersects and it consist all shopping malls and restaurants where bus, three and two wheeler stops frequently in day and night both times.

\begin{tabular}{|c|c|}
\hline Steel Gate & $\begin{array}{l}\text { It is one of prominent point which connects with one of the most corporate head offices, } \\
\text { residential complexes and township of coal mining and steel company's ex. Coal India Ltd. } \\
\text { and Steel Authority of India Ltd. which incorporates almost } 10000 \text { employees except } \\
\text { roadside household peoples. }\end{array}$ \\
\hline Memko More & $\begin{array}{l}\text { It is another intersection point where } 4 \text { road connects each other's. This intersection is well } \\
\text { connected with city and village, also connects with NH-18 and NH-19. }\end{array}$ \\
\hline Big Bazaar & $\begin{array}{l}\text { It is one of the population hub of the city which connects } \mathrm{NH}-18 \text {. It comprises shopping } \\
\text { malls and restaurants and all kinds of vehicles except heavy vehicles stops frequently in this } \\
\text { point. }\end{array}$ \\
\hline Kendua Bazaar & $\begin{array}{l}\text { It is one of the prominent markets which is situated on the road side of NH-18 and it } \\
\text { connects one side with Bank More and another side with Katras Colliery area. }\end{array}$ \\
\hline $\begin{array}{l}\text { Bus Stand, } \\
\text { Bartand }\end{array}$ & $\begin{array}{l}\text { Bartand bus stand is the main bus stand of Dhanbad. It connects with all neighboring cities } \\
\text { like Patna, Asansol, Durgapur, Ranchi, Jamshedpur and all districts of Jharkhand state in } \\
\text { whole day and night through NH-18 \& NH-19. }\end{array}$ \\
\hline Govindpur & $\begin{array}{l}\text { It is one of the coal mining industrial town and junction point of } \underline{\mathrm{NH} 19} \text { and } \underline{\mathrm{NH}} 18 \text { which } \\
\text { connects nearby city Kolkata and Ranchi. This area is under heavy noise pollution due to } \\
\text { all day and night traffic of all kind heavy vehicles, buses and others. It is a divided road } \\
\text { with four lanes (two in each direction). }\end{array}$ \\
\hline $\begin{array}{l}\text { Katras More, } \\
\text { Jharia }\end{array}$ & $\begin{array}{l}\text { Jharia is of the industrial coal town and famous for a underground coal field fire. It is } \\
\text { connected with nearby town Purulia and passes all heavy coal trucks to from coal mines. }\end{array}$ \\
\hline Shramik Chowk & $\begin{array}{l}\text { It is intersection of three roads of Dhanbad city and it is also known as Dhanbad Railway } \\
\text { station chowk. }\end{array}$ \\
\hline Bata More, Jharia & It is one of old intersection of Dhanbad city which has highest no of footwear shops. \\
\hline $\begin{array}{l}\text { Vinod Vihari } \\
\text { Chowk }\end{array}$ & It is situated on the Bhuli - Hirak bypass road which connects with NH-18 and NH-19. \\
\hline Bank More & $\begin{array}{l}\text { It is the most popular junction of Dhanbad city, which has the highest no of shops, coaching } \\
\text { centers and banks. It also junction point of NH-18. }\end{array}$ \\
\hline Dhaunsar More & Dhaunsar more connects Bank more and Jharia township. \\
\hline
\end{tabular}

The collection of noise level data took place during the months of November 2016- May 2017, when roadway temperatures ranged from $25^{\circ} \mathrm{C}$ to $30^{\circ} \mathrm{C}$. At each of the above-mentioned stations, the following parameters were measured: 
* Sound pressure level, using Bruel \& Kjaer 2238 Mediator Integrating Sound Level Meter (According to IS: 3028:1998)

* Traffic volume and their Classification

* Average speed of vehicles $(\mathrm{Km} / \mathrm{h})$

* Geographical Positioning System (GPS meter) using eTrex H, Garmin

The sound pressure level was measured at a distance of $7.5 \pm 0.2$ meter from the centre of the road and at a height of $1.2 \pm 0.1$ meter. GPS points of 15 monitoring stations have been also collected to prepare a study area map by ArcGIS 10.3 software package (Fig. 1). The position of point sources, point receivers, and settlements locations of monitoring stations are depicted in Fig. 2, which was created using the SoundPLAN 7.2 software. Traffic noise monitoring of every points conducted for every 3-hour interval during five different times of the day. Various parameters as maximum peak level as $\mathrm{L}_{\mathrm{AFMaxP}}$, maximum level as $\mathrm{L}_{\mathrm{AFMaxL}}$, minimum level as $\mathrm{L}_{\mathrm{AFMinL}}$, average level as $\mathrm{L}_{\mathrm{Aeq}}, \mathrm{L}_{10}, \mathrm{~L}_{90}$, have been recorded from 2238 sound level meter with fast response mode and "A" frequency weighted. In addition, the $\mathrm{C}$ weighted maximum peak level as LCPKMax was collected to check for impulsive noise throughout that time period. Due to difficulty in installing traffic volume counting videography software in Indian conditions on the roads (because it even counts man, by-cycle, three wheeler Pedal rickshaw \& animals as vehicles and also vehicles with extra goods looks big counts as heavy vehicles), traffic counts were conducted continuously for five different times viz. Morning conditions (6 AM-9 AM, 9 AM- 12 PM), Afternoon conditions( 2 PM - 5 PM), Evening conditions (5 PM- 8 PM), Night conditions (8 PM- 11 PM) in a day manually while noise levels were also collected same times. Vehicles are classified into five different categories.
* Two Wheelers (Motor cycle, scooter)
* Three Wheelers (Tempoo, Auto Rickshaw)
* Four wheelers (Car, Prepaid Taxi, Others)
* Commercial Four/Six Wheelers (Bus/ Trekkars)
* Heavy Vehicles (Trucks/Tractors/Tilors /Goods Vehicles)

Also, different parameters have been calculated from measured level viz. $\mathrm{L}_{\mathrm{Aeq}}, \mathrm{L}_{10}, \mathrm{~L}_{90}, 24 \mathrm{hrs} \mathrm{L}_{\mathrm{dn}}$, Noise Pollution Level (LNP), Traffic Noise Index (TNI), Noise Climate (NC).

\subsection{Radial Noise Diagrams}

Radial noise diagrams have been created to visualize the noise pollution among the 15 monitoring stations. It is created with Microsoft Excel Software Package.

\subsection{Noise Descriptors \& Indexes}

Table 2 shows the descriptions and principles of several noise descriptors $\&$ indexes such as $15 \mathrm{hrs}$ average noise level ( $\left.\mathrm{L}_{\mathrm{Aeq}}\right)$, $\mathrm{L}_{10}, \mathrm{~L}_{90}, 24 \mathrm{hrs} \mathrm{L}_{\mathrm{dn}}$, Noise Pollution Level (LNP), Traffic Noise Index (TNI), Noise Climate (NC) etc. 


\begin{tabular}{|c|c|c|c|c|}
\hline $\begin{array}{l}\text { Sl. } \\
\text { No. }\end{array}$ & $\begin{array}{c}\text { Descriptors \& } \\
\text { Indexes }\end{array}$ & Description & Principle & Explanation \\
\hline 1. & $\mathbf{L}_{\text {Aeq }}$ & $\begin{array}{l}\mathrm{L}_{\text {Aeq }} \text { denotes the equivalent } \\
\text { continuous sound pressure level } \\
\text { that transmits to the receiver the } \\
\text { same amount of acoustic energy as } \\
\text { the fluctuating levels of noise } \\
\text { during the measurement period } \\
\text { (Banerjee et al. 2008b; Garg et al. } \\
\text { 2015; Singh et al. 2016). }\end{array}$ & eq $\left.=10 \log _{10} \sum_{\mathrm{i}=1}^{\mathrm{n}} \mathrm{f} \times \frac{\mathrm{L}_{\mathrm{i}}}{10}\right] \mathrm{dB}(\mathrm{A})$ & $\begin{array}{l}f_{i} \text { is the fraction of time, } L_{i} \text { is the sound level of } \\
i^{\text {th }} \text { time. The significance of } L_{\text {Aeq }} \text { as a noise rating } \\
\text { is that individual noise ratings for different } \\
\text { segments of time can be easily combined to find } \\
\text { the combination's energy average. It is } \\
\text { calculated individually for all the noise hours } \\
\text { and subsequently average also calculated for } \\
\text { five different hours. }\end{array}$ \\
\hline 2. & $\mathbf{L}_{10}$ & $\begin{array}{l}\mathrm{L}_{10} \text { denotes the noise level } \\
\text { exceeded } 10 \text { percent of the time } \\
\text { during the measurement period, } \\
\text { usually the noisiest hour of the day. } \\
\text { (Kumar et al. 2014) }\end{array}$ & & $\begin{array}{l}\text { It indicates the intruding peak level of noise and } \\
\text { it is calculated for every monitoring points of } 15 \\
\text { hrs. }\end{array}$ \\
\hline 3. & L90 & $\begin{array}{l}\mathrm{L}_{90} \text { denotes the noise level } \\
\text { exceeded } 90 \text { percent of the time } \\
\text { during the measurement period. }\end{array}$ & & $\begin{array}{l}\mathrm{L}_{90} \text { level is an indicator of the background noise } \\
\text { level and it is calculated for every monitoring } \\
\text { points of } 15 \text { hrs. (Marathe 2012). }\end{array}$ \\
\hline 4. & $\mathbf{L}_{\mathrm{dn}}$ & $\begin{array}{l}\text { The day night } 24 \text { hrs. equivalent } \\
\text { noise levels of a community can be } \\
\text { expressed in this equation. The day } \\
\text { hours in respect to noise levels } \\
\text { assessment are fixed from } 6 \mathrm{AM} \mathrm{-} 9 \\
\text { PM (i.e., } 15 \mathrm{hrs)} \text { and night hours }\end{array}$ & $\begin{array}{c}\mathrm{L}_{\mathrm{dn}}=10 \log _{10}\left[15 / 24^{10^{L_{d} / 10}+}\right. \\
\left.9 / 2410^{\mathrm{L}_{\mathrm{n}}+10 / 10}\right], \mathrm{dB}(\mathrm{A})\end{array}$ & $\begin{array}{l}\text { where, } \mathrm{L}_{\mathrm{d}} \text { depicts day-equivalent noise levels } \\
\text { (from } 6 \mathrm{AM}-9 \mathrm{PM} \text { ) and } \mathrm{L}_{\mathrm{n}} \text { depicts night } \\
\text { equivalent noise levels (from } 9 \mathrm{PM}-6 \mathrm{AM} \text { ), dB } \\
\text { (A). A sound level of } 10 \mathrm{~dB} \text { is added to Ln due } \\
\text { to the low ambient sound levels during night for } \\
\text { assessing the } \mathrm{L}_{\mathrm{dn}} \text { values. }\end{array}$ \\
\hline
\end{tabular}




\begin{tabular}{|c|c|c|}
\hline & & $\begin{array}{l}\text { from } 9 \text { PM - } 6 \text { AM (i.e., } 9 \text { hrs) } \\
\text { (Banerjee et al. 2008b) }\end{array}$ \\
\hline 5. & $\begin{array}{c}\text { Noise } \\
\text { Pollution } \\
\text { Level (LNP) }\end{array}$ & $\begin{array}{l}\text { Noise pollution level (LNP) } \\
\text { describes the degree of annoyance } \\
\text { caused by fluctuating noise } \\
\text { (Marathe 2012). }\end{array}$ \\
\hline 6. & $\begin{array}{l}\text { Traffic Noise } \\
\text { Index (TNI) }\end{array}$ & $\begin{array}{l}\text { The TNI is another parameter, } T N I=\left[4\left(L_{10}-L_{90}\right)+L_{90}-30\right], \mathrm{dB}(\mathrm{A}) \\
\text { which indicates the degree of } \\
\text { variation in a traffic flow. This } \\
\text { index attempts to make an } \\
\text { allowance for noise variability } \\
\text { concerning } L_{10} \text { level (Banerjee et al. } \\
\text { 2008b; Chowdhury et al. 2012; } \\
\text { Laxmi et al. 2019). }\end{array}$ \\
\hline 7. & $\begin{array}{c}\text { Noise } \\
\text { Climate } \\
\text { (NC) }\end{array}$ & $\begin{array}{l}\text { It is the range over which the sound } \\
\text { levels are fluctuating in an interval } \\
\text { of time (Chowdhury et al. 2012). }\end{array}$ \\
\hline
\end{tabular}




\subsection{Contour Plotting}

Contour plotting has been developed with Minitab 17 software package for better visualization of the noise environment. Minitab plots the $\mathrm{X}$ factor values as Velocity and $\mathrm{Y}$ factors as traffic volume on the $\mathrm{x}$ - and $\mathrm{y}$-axes are predictors, while contour lines and colored bands represent the values for the z-factor as average noise level (response). Five different plots of five different noise hours have been created viz. Morning (6 AM- 9 AM), Morning (9 AM - 12 PM), Afternoon (2 PM - 5 PM), Evening (5 PM - 8 PM), Night (8 PM - 11 PM). These contour plots have developed as average noise level $\mathrm{dB}(\mathrm{A})$ of that hour with respect to vehicle count and average speed of vehicles $(\mathrm{Km} / \mathrm{h})$ of that hour. From these contour plots it can be easily understood at what speed and vehicle count the noise level has increased/decreased among 15 monitoring points of that hour.

\subsection{Multi-layer Perceptron Neural Network}

In this study multi-layer perceptron (MLP) neural network have been used. It has been done through IBM SPSS Version 21.0 Software. The architecture of MLP network consists of interconnection of several layers as discussed above about three layers and it can have one or two hidden layers. Biological neurons as a basic processing unit transmits information or signals from input to output layer through the synaptic joints (Bravo-Moncayo et al. 2019). Activation is a specific mathematical function of a neuron. Activation accepts inputs from the previous layer through neuron and produces output for the next succeeding layer. If network contains two hidden layers, activation function is same on both layers. The output layer is the weighted sum of all hidden layer outputs and subsequently produces model (Avşar et al. 2004).

Two types of activation functions generally used in neural network; they are Hyperbolic tangent and Sigmoid. This both functions take real valued arguments and transforms in the range of viz. Hyperbolic $(-1,1)$ and Sigmoid $(0,1)$.

For the development of model different parameters have been used viz. no. of vehicles as traffic volume, vehicle speed, \% of heavy vehicles, traffic flow adjustment, distance adjustment, gradient adjustment, pavement adjustment and noise levels data are used (Debnath and Singh, 2018).

Where, $\mathrm{V}$ is the mean traffic speed that depends on road classification as specified by CoRTN model and $\mathrm{P}$ is the percentage of heavy vehicles given by

$$
\Delta_{f}(\text { Traffic flow adjustment })=33 \log _{10}\left(V+40+\frac{500}{V}\right)+10 \log _{10}\left(1+\frac{5 P}{V}\right)-68
$$

Where, $f$ is the hourly flow of heavy vehicles and $\mathrm{q}$ is total hourly flow.

$$
p=\frac{100 f}{q} .
$$

$$
\Delta_{g}(\text { Gradient adjustment })=0.3 \mathrm{G}
$$

$$
\Delta_{d}(\text { Distance adjustment })=-10 \log _{10}\left(\frac{d^{\prime}}{13.5}\right)
$$

Where, $d^{\prime}$ is the shortest slant distance from the source position given by

$$
d^{\prime}=\sqrt{ }(\mathrm{d}+3.5)^{2}+h^{2},
$$


$297 \mathrm{~d}$ is the shortest horizontal distance between the nearside carriageway edge and the reception point, and $h$ is the vertical 298 distance between the source position and the reception point.

300 Where, $\mathrm{P}$ is the percentage of heavy vehicles.

301 The data was processed using IBM SPSS Version 21.0 Package. $\mathrm{L}_{\mathrm{Aeq}}$ observed as output parameters. In comparison 302 to prior researches, this is a huge sample size that would allow for the development of a generally recognized ANN 303 model. The whole methodology of this paper has been discussed in a fig. 3 as a flowsheet.

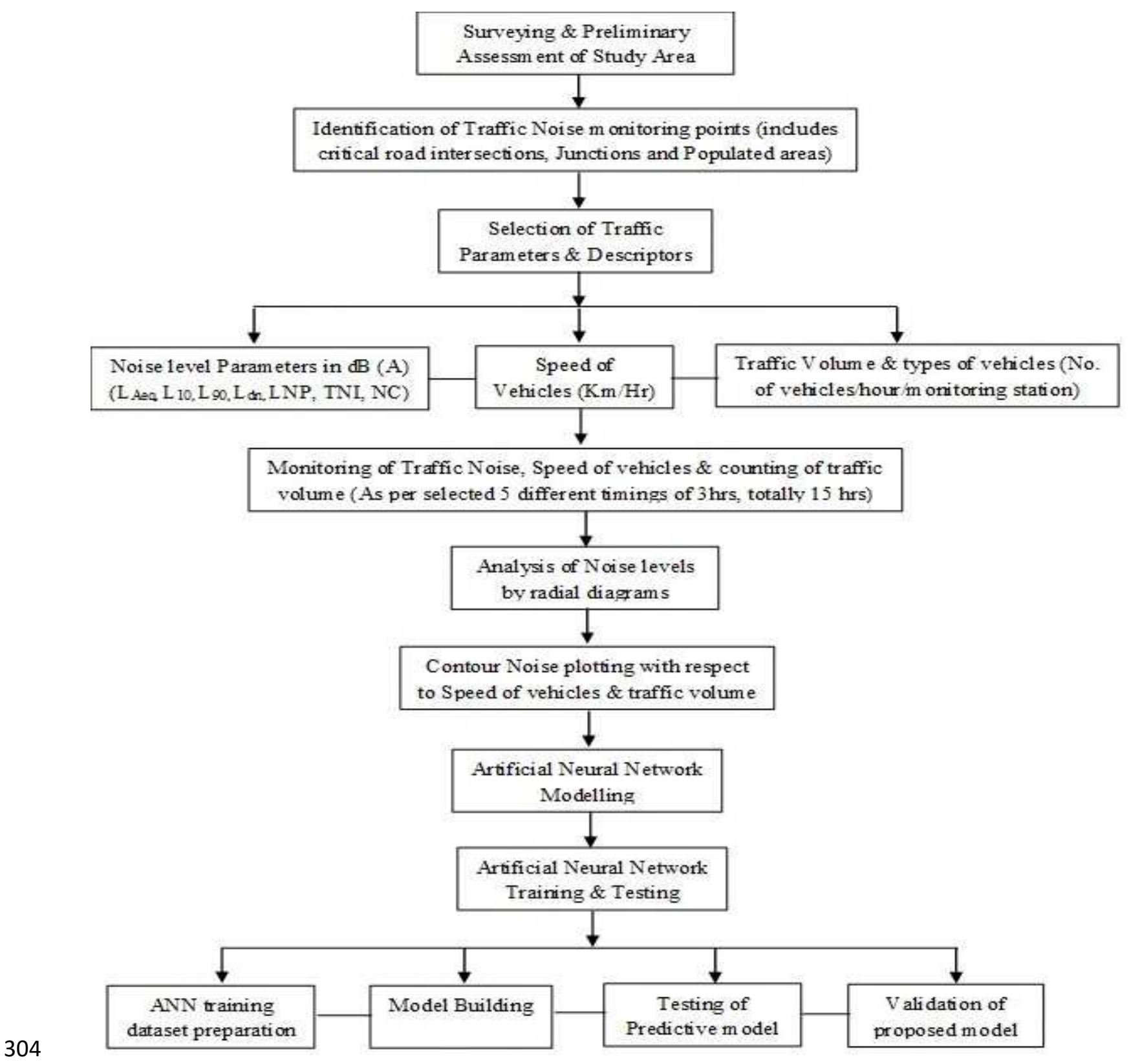

Fig. 3 Flow-sheet of Methodology 


\subsection{Results \& Discussions}

\subsubsection{Noise level analysis}

Noise level recorded from Sound Level Meter have been analyzed according to peak and non-peak hours of

309 five different timings viz.

* Peak morning hours (9 AM - 12 PM)

* Non-Peak Afternoon hours (2 PM - 5 PM)

* Peak Evening hours (5 PM - 8 PM)

* Non-Peak Night hours (8 PM - 11 PM)

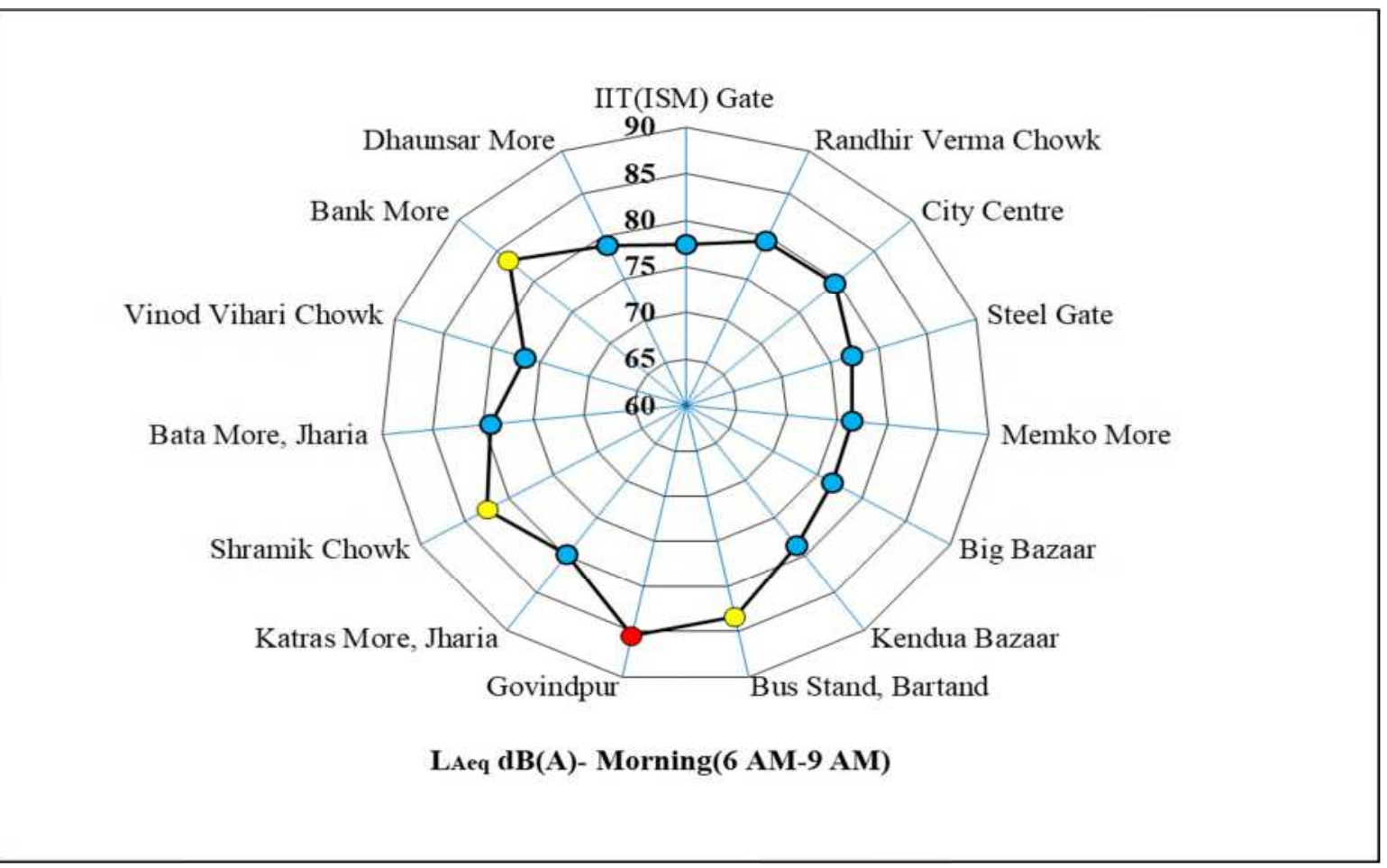

Fig. 4(a) Radial figures of Dhanbad township area during Non-Peak morning hours (6 AM - 9 AM)

317 Fig. 4(a) depicts LAeq (average) of Dhanbad township area during Non-Peak morning hours, where only four stations

318 (Bank More, Shramik Chowk, Govindpur, and Bus Stand Bartand) were higher than $80 \mathrm{~dB}(\mathrm{~A})$ out of 15 monitoring 319 locations. The peak level of this noise hours (6 $\mathrm{AM}-9 \mathrm{AM})$ is $85.5 \mathrm{~dB}(\mathrm{~A})$ and it is concluded that average noise 320 levels all of the monitoring points are beyond the permissible limit, given under The Noise Pollution (Regulation and 321 Control) Rules, 2000 of the Environment (Protection) Act. 1985. 


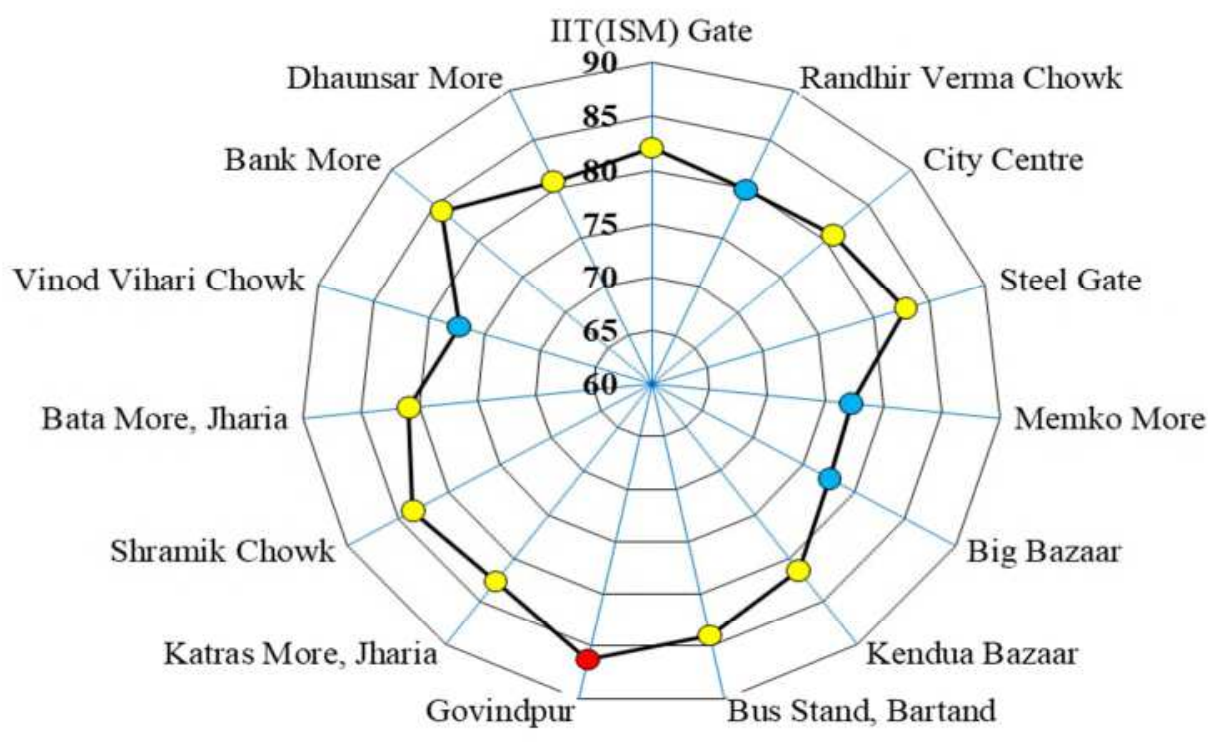

LAeq dB(A)- Morning(9 AM-12 PM)

Fig. 4(b) Radial figures of Dhanbad township area during Peak morning hours (9 AM - 12 PM)

324 Fig. 4(b) depicts LAeq (average) of Dhanbad township area during peak morning hours, where 11 out of 15 monitoring locations (Bank More, Shramik Chowk, Govindpur, Bus Stand Bartand, Bata More Jharia, Steel Gate, and others) were higher than $80 \mathrm{~dB}(\mathrm{~A})$. The peak level of this noise hours (9 AM-12 PM) is $86.3 \mathrm{~dB}(\mathrm{~A})$ [Govindpur] and it is concluded that average noise levels all of the monitoring points are beyond the permissible limit, given under The

328 Noise Pollution (Regulation and Control) Rules, 2000 of the Environment (Protection) Act. 1985. Compare to 6 AM to $9 \mathrm{AM}$ noise level in this segment is higher. 


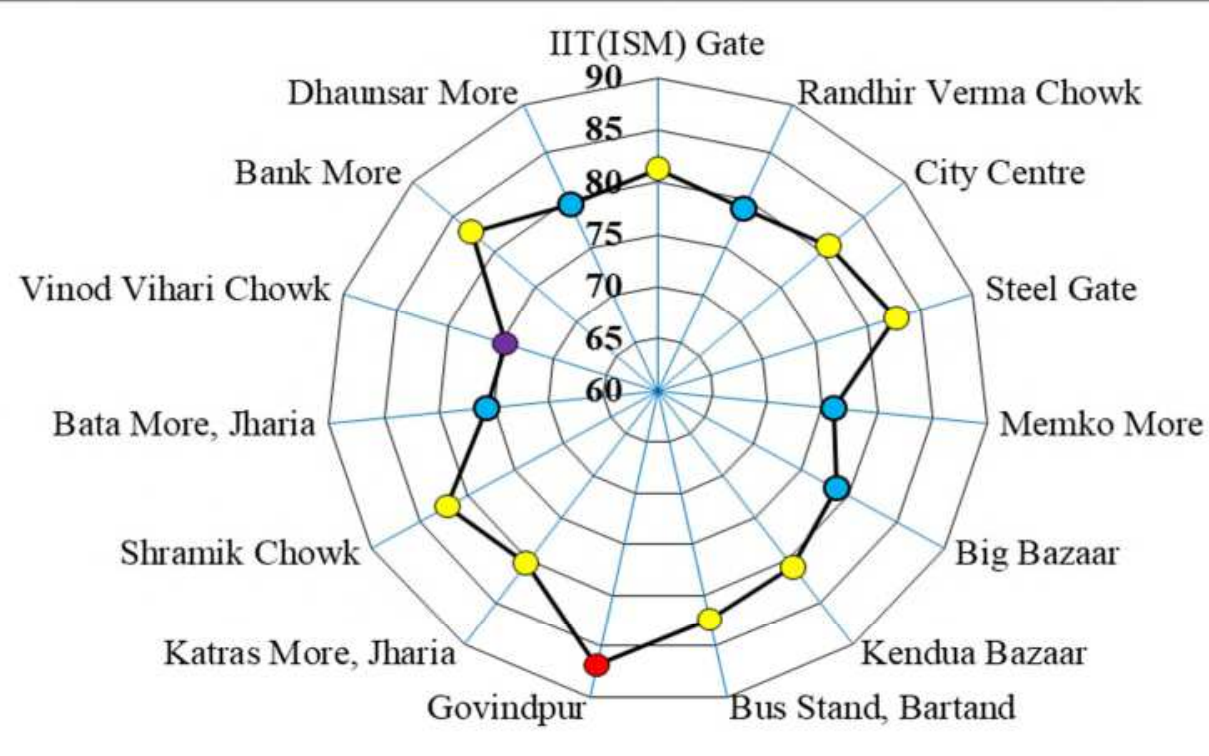

LAeq dB(A)- Afternoon(2 PM-5 PM)

Fig. 4(c) Radial figures of Dhanbad township area during Non-Peak Afternoon hours (2 PM - 5 PM)

332 Fig. 4(c) depicts LAeq (average) of Dhanbad township area during Non-Peak Afternoon hours, where we can see that 333 out of 15 monitoring locations, 9 stations (Bank More, Shramik Chowk, Govindpur, Bus Stand Bartand, and others) were higher than $80 \mathrm{~dB}(\mathrm{~A})$. The peak level of this noise hours (2 PM - $5 \mathrm{PM})$ is $86.9 \mathrm{~dB}(\mathrm{~A})$ [Govindpur] and minimum level have been found at Vinod Vihari Chowk [74.6]. As Vinod Vihari Chowk is one of the small industry area and the Environment (Protection) Act. 1985. 
IIT(ISM) Gate

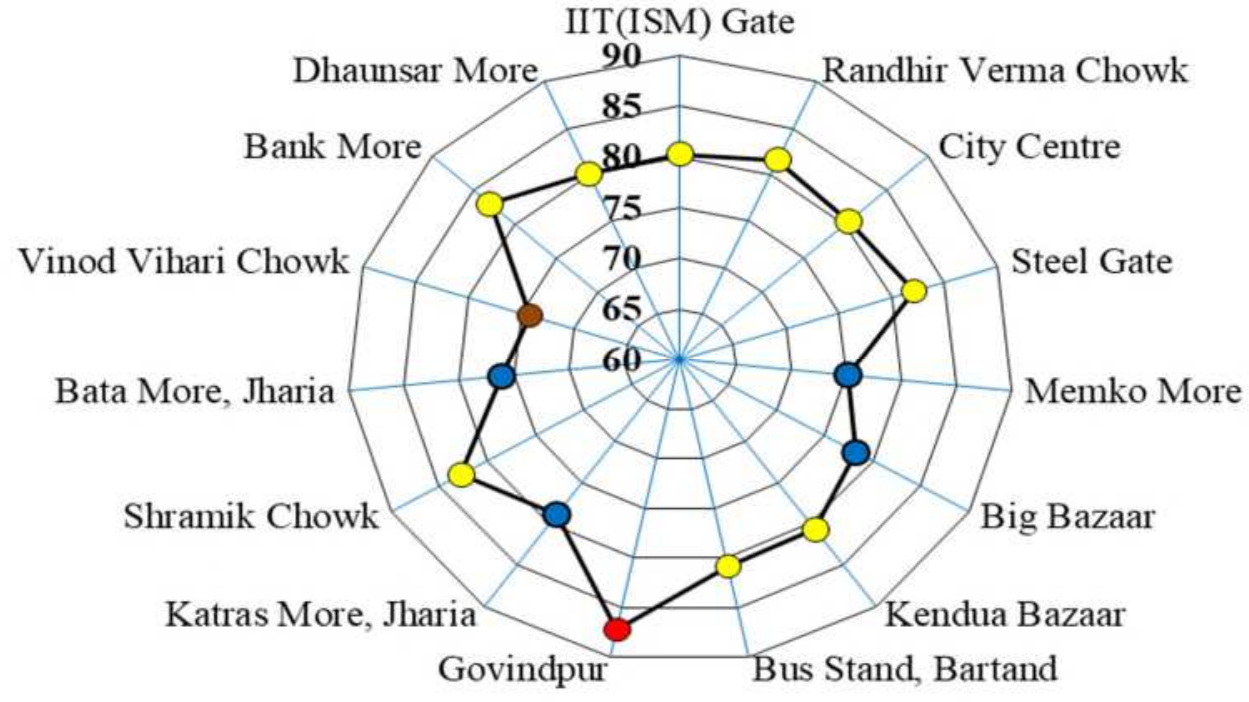

LAeq dB(A)-Evening(5 PM-8 PM)

Fig. 4(d) Radial figures of Dhanbad township area during Peak Evening hours (5 PM - 8 PM)

341 Fig. 4(d) depicts $\mathrm{L}_{\text {Aeq }}$ (average) of Dhanbad township area during Peak Evening hours, where we can observe out of

34215 monitoring points 10 stations (viz. Bank More, Shramik Chowk, Govindpur, Bus Stand Bartand) were higher than

$34380 \mathrm{~dB}(\mathrm{~A})$. The peak level of this noise hours (5 PM - $8 \mathrm{PM}$ ) is $87.2 \mathrm{~dB}(\mathrm{~A})$ and minimum level is $74.2 \mathrm{~dB}(\mathrm{~A})$. Noise

344 level of this segment is little higher than afternoon noise hours but little less than that of morning 9AM to 12 PM noise

345 hours. Though the average noise levels all of the monitoring points are beyond the permissible limit, given under The

346 Noise Pollution (Regulation and Control) Rules, 2000 of the Environment (Protection) Act. 1985. 


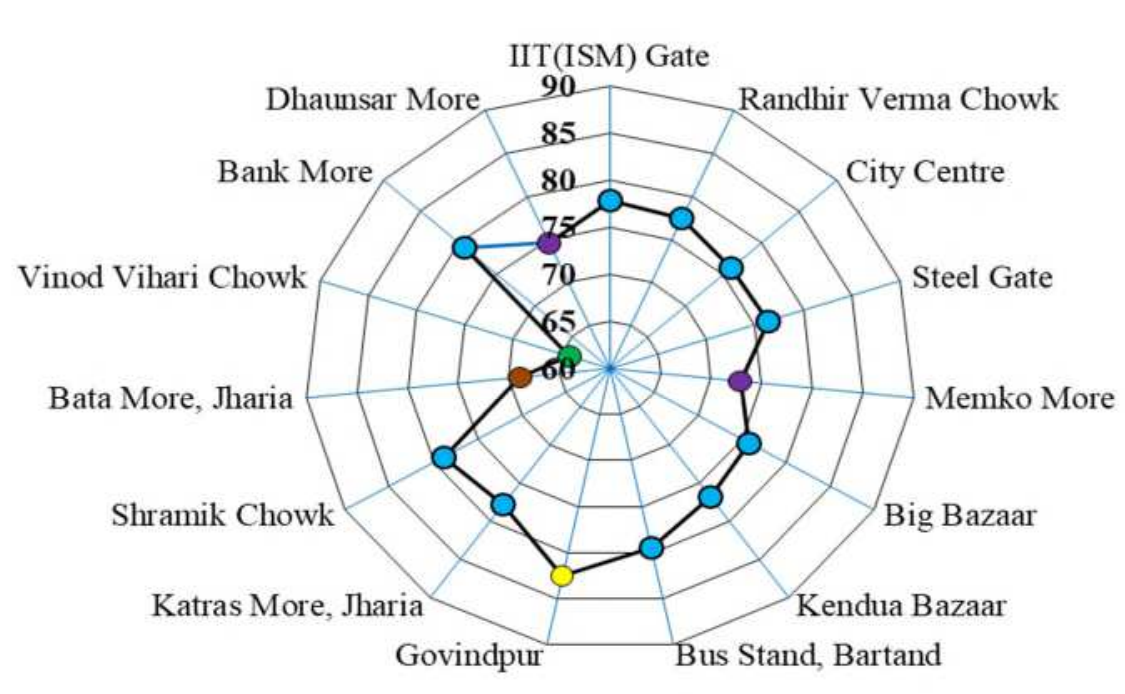

LAeq dB(A)- Night(8 PM-11 PM)

Fig. 4(e) Radial figures of Dhanbad township area during Non-Peak Night hours (8 PM - 11 PM)

Fig. 4(e) depicts $\mathrm{L}_{\text {Aeq }}$ (average) of Dhanbad township area during Non-Peak Night hours, where we can observe out of 15 monitoring points only 1 station (Govindpur) were higher than $80 \mathrm{~dB}(\mathrm{~A})$. The peak level of this noise hours (8 $\mathrm{PM}-11 \mathrm{PM}$ ) is $82.5 \mathrm{~dB}(\mathrm{~A})$ [Govindpur] and minimum level is $64.2 \mathrm{~dB}(\mathrm{~A})$ [Vinod Vihari Chowk]. 8 PM to $11 \mathrm{PM}$ among the lowest noise level hours compared to other four noise hours. The average noise levels all of the monitoring points are beyond the permissible limit, given under The Noise Pollution (Regulation and Control) Rules, 2000 of the Environment (Protection) Act. 1985.

From the above all radial diagrams of trend of Peak and Non-Peak hours shows the noise level have been exceeded the permissible limit in all of the stations except Non-Peak Night hours (8 PM- 11 PM). Several stations viz Bank More, Shramik Chowk, Govindpur, Bus Stand Bartand, Bata More Jharia, Steel Gate and others have exceeded 80 $\mathrm{dB}(\mathrm{A})$ and maximum noise level found in Govindpur station during in during day and night hours.

\subsubsection{Traffic Flow Characterization:}

The composition of the average percentage of vehicle fleet/day passes in Dhanbad Township as follows: $19.37 \%$ are four- wheelers (car, taxi, others), $17.47 \%$ as three wheelers (tempoo, auto rickshaw), 59.07\% two-wheelers (motor cycle, scooter), $1.22 \%$ buses $\&$ trekkers and $2.87 \%$ trucks/tractors/tilors/goods vehicles.

Two wheelers are the highest no. of vehicles passes among the monitoring station. Table 3 shows the total no. of vehicles counted during 5 different time-frame of morning, afternoon, evening and night hours in all monitoring stations. This is the average composition of vehicles which have been collected from road traffic of Dhanbad Township. However, owing to the huge number of data sets, each of the 15 monitoring stations has a unique vehicle fleet composition, which is not displayed. Highest no. of vehicles counted during 9 AM to 12 PM, following by 5 Pm to $8 \mathrm{Pm}$. Daytime flow accounted for $64.01 \%$ of the total vehicles for both day and night. Furthermore, a higher 
number of trucks/goods vehicles and fewer buses were observed on business days. In general, traffic on business days exceeds that of non-business days by $60 \%$ excluding heavy vehicles.

371 Table 3 Total no. of vehicles counted during 5 different time-frame of morning, afternoon, evening and night hours

372 in all monitoring stations

\begin{tabular}{|c|c|c|c|c|c|}
\hline Location Name & $\begin{array}{c}\text { Total Vehicles } \\
\text {-Morning (6-9 } \\
\text { AM) }\end{array}$ & $\begin{array}{l}\text { Total Vehicles } \\
\text {-Morning (9 } \\
\text { AM-12 PM) }\end{array}$ & $\begin{array}{l}\text { Total Vehicles - } \\
\text { Afternoon (2-5 } \\
\text { PM) }\end{array}$ & $\begin{array}{c}\text { Total Vehicles - } \\
\text { Evening (5-8 } \\
\text { PM) }\end{array}$ & $\begin{array}{l}\text { Total Vehicles - } \\
\text { Night (8-11 PM) }\end{array}$ \\
\hline IIT(ISM) Gate & 4652 & 10000 & 8367 & 8915 & 4199 \\
\hline $\begin{array}{c}\text { Randhir } \\
\text { Verma Chowk }\end{array}$ & 4152 & 10445 & 9065 & 10838 & 4290 \\
\hline City Centre & 4761 & 10067 & 7903 & 8517 & 2992 \\
\hline Steel Gate & 5143 & 9847 & 5718 & 7147 & 4597 \\
\hline Memko More & 3514 & 6568 & 7644 & 5839 & 2393 \\
\hline Big Bazaar & 3125 & 3498 & 4117 & 4614 & 1858 \\
\hline $\begin{array}{l}\text { Kendua } \\
\text { Bazaar }\end{array}$ & 4388 & 7592 & 6148 & 6380 & 3400 \\
\hline $\begin{array}{l}\text { Bus Stand, } \\
\text { Bartand }\end{array}$ & 4507 & 9129 & 6332 & 7253 & 4481 \\
\hline Govindpur & 5591 & 8511 & 7824 & 6546 & 2714 \\
\hline $\begin{array}{c}\text { Katras More, } \\
\text { Jharia }\end{array}$ & 2763 & 5813 & 6012 & 6011 & 3513 \\
\hline $\begin{array}{l}\text { Shramik } \\
\text { Chowk }\end{array}$ & 7298 & 15269 & 9229 & 9364 & 6596 \\
\hline $\begin{array}{l}\text { Bata More, } \\
\text { Jharia }\end{array}$ & 1321 & 2701 & 1991 & 2628 & 1480 \\
\hline $\begin{array}{c}\text { Vinod Vihari } \\
\text { Chowk }\end{array}$ & 1882 & 3216 & 2261 & 2086 & 1374 \\
\hline Bank More & 7337 & 11762 & 11212 & 11675 & 6925 \\
\hline Dhansar More & 4022 & 8877 & 7692 & 8539 & 5421 \\
\hline
\end{tabular}

\subsubsection{Noise Descriptors \& Indexes}


These descriptor and indexes has been calculated from recorded noise level from all 15 monitoring points across Dhanbad township and presented in Table 4.

Table $4 \mathrm{~L}_{10}, \mathrm{~L}_{90}, \mathrm{~L}_{\mathrm{dn}} \&$ Noise Pollution Level (LNP), Traffic Noise Index (TNI), Noise Climate (NC) of 15 monitoring 381 stations

\begin{tabular}{|c|c|c|c|c|c|c|c|}
\hline Location Name & $\begin{array}{c}L_{\text {Aeq }} \\
\operatorname{dB}(A)\end{array}$ & $\begin{array}{c}L_{10} \\
\mathrm{~dB}(A)\end{array}$ & $\begin{array}{c}\text { L90 } \\
\text { dB(A) }\end{array}$ & $\begin{array}{c}24 \text { Hrs } \\
L_{d n} \\
\text { dB(A) }\end{array}$ & $\begin{array}{c}\text { Noise } \\
\text { Pollution } \\
\text { Level (LNP) } \\
\text { dB(A) }\end{array}$ & $\begin{array}{l}\text { Traffic } \\
\text { Noise } \\
\text { Index } \\
\text { (TNI) } \\
\text { dB(A) }\end{array}$ & $\begin{array}{c}\text { Noise } \\
\text { Climate } \\
\text { (NC) dB(A) }\end{array}$ \\
\hline IIT(ISM) Gate & 79.8 & 102.8 & 63.8 & 85.7 & 118.7 & 189.6 & 38.9 \\
\hline $\begin{array}{c}\text { Randhir Verma } \\
\text { Chowk }\end{array}$ & 79.5 & 102.5 & 63.6 & 86.0 & 118.4 & 189.1 & 38.9 \\
\hline City Centre & 79.6 & 102.5 & 63.6 & 85.0 & 118.4 & 189.1 & 38.9 \\
\hline Steel Gate & 80.3 & 103.3 & 64.2 & 85.9 & 119.3 & 190.5 & 39.1 \\
\hline Memko More & 75.6 & 98.1 & 53.0 & 80.9 & 120.7 & 203.5 & 45.1 \\
\hline Big Bazaar & 77.4 & 100.2 & 61.9 & 83.6 & 115.6 & 184.8 & 38.2 \\
\hline Kendua Bazaar & 79.7 & 102.6 & 63.7 & 85.4 & 118.6 & 189.4 & 38.9 \\
\hline $\begin{array}{c}\text { Bus Stand, } \\
\text { Bartand }\end{array}$ & 82.0 & 105.2 & 65.6 & 87.2 & 121.6 & 194.0 & 39.6 \\
\hline Govindpur & 85.7 & 109.2 & 70.7 & 91.5 & 124.2 & 195.0 & 38.6 \\
\hline $\begin{array}{c}\text { Katras More, } \\
\text { Jharia }\end{array}$ & 79.9 & 102.9 & 64.0 & 85.3 & 118.9 & 189.9 & 39.0 \\
\hline Shramik Chowk & 81.9 & 105.1 & 66.9 & 87.5 & 120.1 & 189.7 & 38.2 \\
\hline $\begin{array}{c}\text { Bata More, } \\
\text { Jharia }\end{array}$ & 76.2 & 98.8 & 53.6 & 80.5 & 121.4 & 204.5 & 45.2 \\
\hline $\begin{array}{c}\text { Vinod Vihari } \\
\text { Chowk }\end{array}$ & 73.4 & 95.7 & 51.0 & 77.6 & 118.1 & 199.7 & 44.7 \\
\hline Bank More & 82.5 & 105.8 & 67.5 & 87.9 & 120.8 & 190.5 & 38.3 \\
\hline Dhaunsar More & 78.8 & 101.7 & 55.9 & 84.2 & 124.5 & 208.9 & 45.8 \\
\hline
\end{tabular}
6 AM to 11 PM noise hours ranged between 95.7-109.2 dB (A) with a mean value of $102.4 \mathrm{~dB}$ (A) and $\mathrm{L}_{90}$ ranged between $51.0-70.7 \mathrm{~dB}(\mathrm{~A})$ with a mean value of $61.9 \mathrm{~dB}(\mathrm{~A})$. The stations where $\mathrm{L}_{10}$ and $\mathrm{L}_{90}$ values are higher than $100 \& 60 \mathrm{~dB}(\mathrm{~A})$ are heavy traffic areas or junction points or presence of big markets. But $\mathrm{L}_{10}$ and $\mathrm{L}_{90}$ level less than $100 \& 60 \mathrm{~dB}$ (A) recorded in commercial, residential areas or less market areas. The observed range of $\mathrm{L}_{10}$ mostly depends on honking of horns in heavy traffic areas when vehicles plying through and noise level was distributed over 
389 the time homogenously. But whereas $\mathrm{L}_{90}$ distributed heterogeneously and mostly depends on hourly traffic volume 390 passing through the road. Due to higher $\mathrm{L}_{90}$ as background noise level becomes higher, people living in that area feels 391 annoyance which could lead to health effects. It has been observed from the Table 4 that as $\mathrm{L}_{10}$ and $\mathrm{L}_{90}$ becomes lower 392 results higher TNC, LNP, NC values.

$393 \mathrm{~L}_{\mathrm{dn}}$ for $24 \mathrm{hrs}$ (including $15 \mathrm{hrs}$ in day time and $9 \mathrm{hrs}$ in night time) ranges from 77.6 to $91.5 \mathrm{~dB}(\mathrm{~A})$ with a mean value 394 of $84.9 \mathrm{~dB}(\mathrm{~A}) . \mathrm{L}_{\mathrm{dn}}$ is better descriptor of noise which has been calculated for all stations. Except 2 stations maximum 395 station are fall in higher $\mathrm{L}_{\mathrm{dn}}$ range. Lower $\mathrm{L}_{\mathrm{dn}}$ value depicts the area is under vegetation (forests, gardens) which act 396 as a noise attenuator.

397

398

399

400

401

402

403

404

405

406

407

408 


\begin{tabular}{|c|c|c|c|c|c|c|c|c|c|c|c|c|c|c|c|}
\hline Timing & \multicolumn{3}{|c|}{6 AM- 9 AM } & \multicolumn{3}{|c|}{9 AM - 12 PM } & \multicolumn{3}{|c|}{2 PM- 5 PM } & \multicolumn{3}{|c|}{5 PM - 8 PM } & \multicolumn{3}{|c|}{8 PM- 11 PM } \\
\hline Location Name & LNP & TNI & $\mathrm{NC}$ & LNP & TNI & $\mathrm{NC}$ & LNP & TNI & $\mathrm{NC}$ & LNP & TNI & NC & LNP & TNI & NC \\
\hline IIT(ISM) Gate & 115.6 & 184.8 & 38.2 & 121.7 & 194.2 & 39.6 & 120.7 & 192.6 & 39.4 & 119.4 & 190.6 & 39.1 & 116.1 & 185.6 & 38.3 \\
\hline $\begin{array}{c}\text { Randhir Verma } \\
\text { Chowk }\end{array}$ & 118.4 & 189.0 & 38.9 & 118.9 & 189.8 & 39.0 & 118.0 & 188.4 & 38.8 & 121.1 & 193.2 & 39.5 & 115.8 & 185.0 & 38.3 \\
\hline City Centre & 118.6 & 189.4 & 38.9 & 120.2 & 191.8 & 39.3 & 120.0 & 191.6 & 39.2 & 119.5 & 190.8 & 39.1 & 113.8 & 182.0 & 37.8 \\
\hline Steel Gate & 115.4 & 184.4 & 38.2 & 122.8 & 195.8 & 39.9 & 122.5 & 195.4 & 39.8 & 121.7 & 194.2 & 39.6 & 114.3 & 182.8 & 37.9 \\
\hline Memko More & 121.8 & 205.1 & 45.3 & 122.6 & 206.2 & 45.4 & 121.2 & 204.2 & 45.2 & 120.2 & 202.8 & 45.0 & 117.5 & 198.9 & 44.6 \\
\hline Big Bazaar & 114.7 & 183.4 & 38.0 & 115.9 & 185.2 & 38.3 & 117.3 & 187.4 & 38.6 & 116.8 & 186.6 & 38.5 & 113.5 & 181.6 & 37.7 \\
\hline Kendua Bazaar & 117.3 & 187.4 & 38.6 & 120.8 & 192.8 & 39.4 & 120.0 & 191.6 & 39.2 & 119.9 & 191.4 & 39.2 & 114.8 & 183.6 & 38.0 \\
\hline $\begin{array}{c}\text { Bus Stand, } \\
\text { Bartand }\end{array}$ & 123.4 & 196.8 & 40.0 & 124.2 & 198.0 & 40.2 & 122.1 & 194.8 & 39.7 & 120.0 & 191.6 & 39.2 & 118.4 & 189.0 & 38.9 \\
\hline Govindpur & 124.1 & 194.7 & 38.6 & 124.9 & 195.8 & 38.6 & 125.6 & 196.7 & 38.7 & 125.9 & 197.1 & 38.7 & 120.8 & 190.5 & 38.3 \\
\hline $\begin{array}{c}\text { Katras More, } \\
\text { Jharia }\end{array}$ & 118.9 & 189.8 & 39.0 & 122.5 & 195.4 & 39.8 & 119.5 & 190.8 & 39.1 & 117.4 & 187.6 & 38.6 & 116.3 & 185.8 & 38.4 \\
\hline Shramik Chowk & 120.8 & 190.5 & 38.3 & 122.0 & 192.0 & 38.4 & 120.3 & 189.9 & 38.2 & 121.0 & 190.8 & 38.3 & 116.7 & 185.3 & 37.9 \\
\hline Bata More, Jharia & 125.2 & 209.8 & 45.9 & 127.1 & 212.5 & 46.2 & 120.8 & 203.7 & 45.1 & 121.4 & 204.5 & 45.2 & 112.7 & 192.1 & 43.8 \\
\hline $\begin{array}{l}\text { Vinod Vihari } \\
\text { Chowk }\end{array}$ & 121.9 & 205.2 & 45.3 & 122.8 & 206.4 & 45.5 & 119.5 & 201.8 & 44.9 & 119.0 & 201.1 & 44.8 & 107.0 & 184.1 & 42.8 \\
\hline Bank More & 121.7 & 191.8 & 38.3 & 122.6 & 192.9 & 38.4 & 121.1 & 190.9 & 38.3 & 121.3 & 191.2 & 38.3 & 117.1 & 185.9 & 37.9 \\
\hline Dhaunsar More & 124.7 & 209.1 & 45.8 & 126.8 & 212.2 & 46.1 & 125.5 & 210.3 & 45.9 & 126.1 & 211.2 & 46.0 & 119.5 & 201.8 & 44.9 \\
\hline
\end{tabular}


411 The mean value of noise pollution level (LNP) is $120.0 \mathrm{~dB}(\mathrm{~A})$, with a range of $115.6-124.5 \mathrm{~dB}(\mathrm{~A})$. As previously

412 stated LNP is the degree of annoyance caused by fluctuating noise (Marathe 2012) and it is calculated as difference

413 between $10 \%$ and $90 \%$ noise plus the average noise level. The Traffic Noise Index (TNI) measures the degree of

414 variation in a traffic flow with respect to $L_{10}$, and it varies between $184.8-208.9 \mathrm{~dB}$ (A) with a mean value of 193.9

$415 \mathrm{~dB}(\mathrm{~A})$. Noise Climate (NC) ranges between 38.2 to $45.8 \mathrm{~dB}(\mathrm{~A})$ with a mean value of $40.5 \mathrm{~dB}(\mathrm{~A})$. The TNI and LNP

416 values are significantly higher, ranges from 100 to $200 \mathrm{~dB}(\mathrm{~A})$ and even exceeding $200 \mathrm{~dB}(\mathrm{~A})$ in some places. These

417 values clearly indicated that high annoyance level in Dhanbad township. From Table 4 it is observed that if we

418 compared between $\mathrm{L}_{\text {Aeq }} \& \mathrm{LNP}$ and $\mathrm{L}_{\text {Aeq }} \&$ TNI noise levels for all the monitoring locations revealed that TNI \& LNP

419 level much more than respective $\mathrm{L}_{\text {Aeq }}$ levels. From Table 4 it is clearly understand that noise levels on any period of

420 the day termed as constant but the presence of single event noise values affects percentile levels and called as TNI or

421 even as up to LNP. LNP, TNI and NC of five different noise hours individually have been shown in Table 5.

422 These descriptors though have limited acoustic effects compared to equivalent noise level but they represent the 423 annoyance and disturbing effects, within the peak levels exceeded over 10\%, 90\% times of noise events. In case day424 night exposure, it reflects the diurnal variation across the Dhanbad township by considering day and night hours noise 425 levels. Similar way due to high fluctuation level and variations over flow conditions Noise Pollution Level (LNP), 426 Traffic Noise Index (TNI), Noise Climate (NC) has been taken into consideration to explore the extent of pollution 427 level in roadside areas. Also the Traffic Noise Index (TNI) values helps to explore the distance effect in case of 428 allocation of new lands, land-use zoning of any area for infrastructure purposes, or any requirement of placing of extra 429 insulation or acoustic barriers needed in present roadside buildings.

\subsubsection{Contour noise plotting}

Contour noise plots for all peak and non-peak hours under different noise hours have been developed by

432 Minitab 17.0 software package. All the plots have been developed as average noise level $\mathrm{dB}(\mathrm{A})$ of that hour with 433 respect to vehicle count and average speed of vehicles $(\mathrm{Km} / \mathrm{h})$ of that hour. By analyzing contour plots, it can be easily 434 concluded that at what context noise level of that monitoring points have been increased or decreased. Every contour 435 plot depicted with color colour from Green to Red for better visualization. 


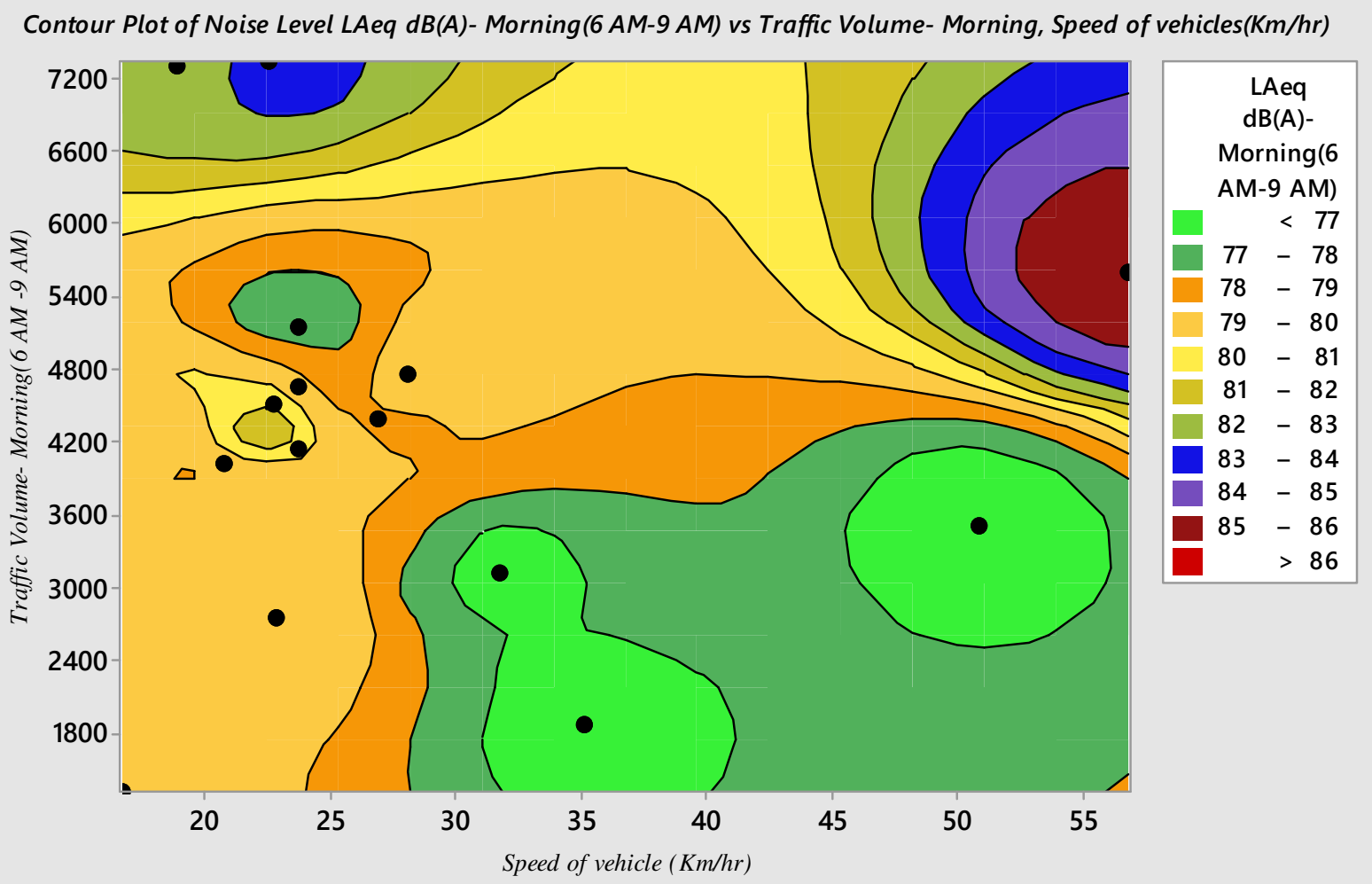

Fig. 5(a) Contour noise plotting of Non-Peak Morning Hours (6 AM - 9 AM) w.r.t Traffic Volume \& Speed of vehicles $(\mathrm{Km} / \mathrm{h})$

440 Fig. 5(a) shows the contour plot of Non-Peak Morning Hours (6 AM - 9 AM). At traffic volume 4000 or more than 441 that and with velocity between $20-30 \mathrm{Km} / \mathrm{h}$ the vehicles noise level exceeded $80 \mathrm{~dB}(\mathrm{~A})$ on some monitoring points, it 442 is mainly due to the traffic on the road and these points are main junction points of the Dhanbad township. But at the same time when velocity increases up to 45 to $55 \mathrm{Km} / \mathrm{h}$ noise level gradually increases due to school buses, college 444 buses, office buses, trespassers to reach markets and other shopkeeper to reach their destination at the 6 AM to 9 AM 445 timing. For the noise level data, the contour plot shows that the highest noise levels were found near an average speed 446 of $55 \mathrm{~km} / \mathrm{h}$ and average traffic volume between 5100 to 6900 . The lowest noise levels were found in shallow streams regardless of the speed of vehicles at an average traffic volume of 1800-2400. 


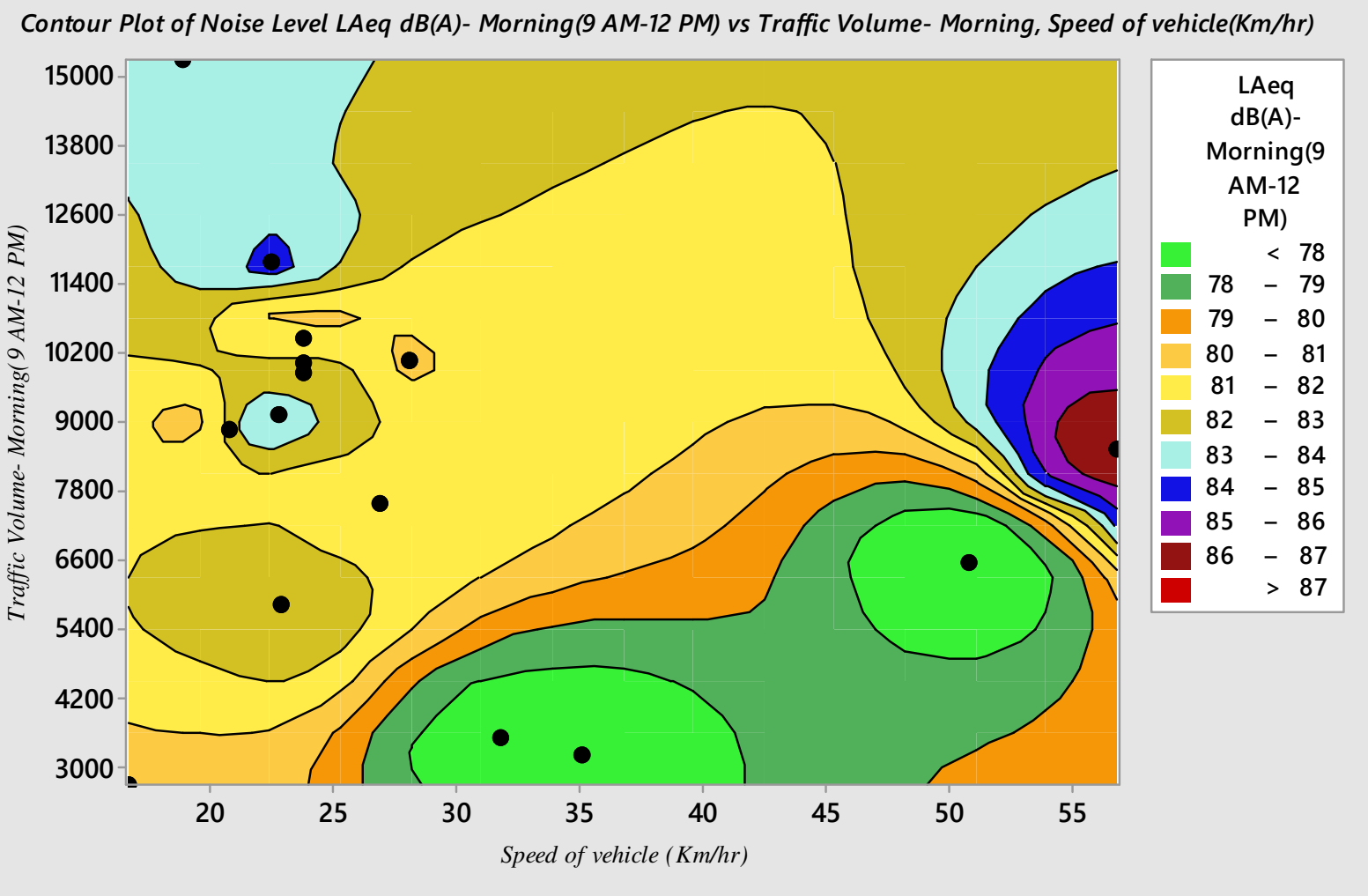

Fig. 5(b) Contour noise plotting of Peak Morning Hours (9 AM - 12 PM) w.r.t Traffic Volume \& Speed of vehicles

$(\mathrm{Km} / \mathrm{h})$

451 Fig. 5(b) shows the contour plot of Peak Morning Hours (9 AM-12 PM). As a peak hour, this noise segment has the more no. of vehicles trespassing the township and clearly shows that the speed of vehicles divides noise levels in two sides like. $20-30 \mathrm{~km} / \mathrm{h}$ and $45-55 \mathrm{~km} / \mathrm{h}$. At traffic volume $9000-12600$ or more than that and with velocity between $20-30 \mathrm{Km} / \mathrm{h}$ the vehicles noise level exceeded $80 \mathrm{~dB}(\mathrm{~A})$ on some monitoring points, it is mainly due to the traffic jam on morning hours persons to reach offices or departments, school buses at peak, students to reaching their respective colleges, markets handing the encroachments to sell daily useable products. As the velocity increases up to 50 to 55 $\mathrm{Km} / \mathrm{h}$ noise level gradually increases at around 7800-12600 due to mainly two wheelers, three wheelers, and the extent to heavy vehicles entering the city at hurry to ensure supplies before closing time heavy vehicles plying towards city.

459 For the noise level data, the contour plot shows that the highest noise levels were found near an average speed of 55 $\mathrm{km} / \mathrm{h}$ and average traffic volume of around 9000 . The lowest noise levels were found in shallow streams regardless of the speed of vehicles at an average traffic volume of 3000 to 5000 . 


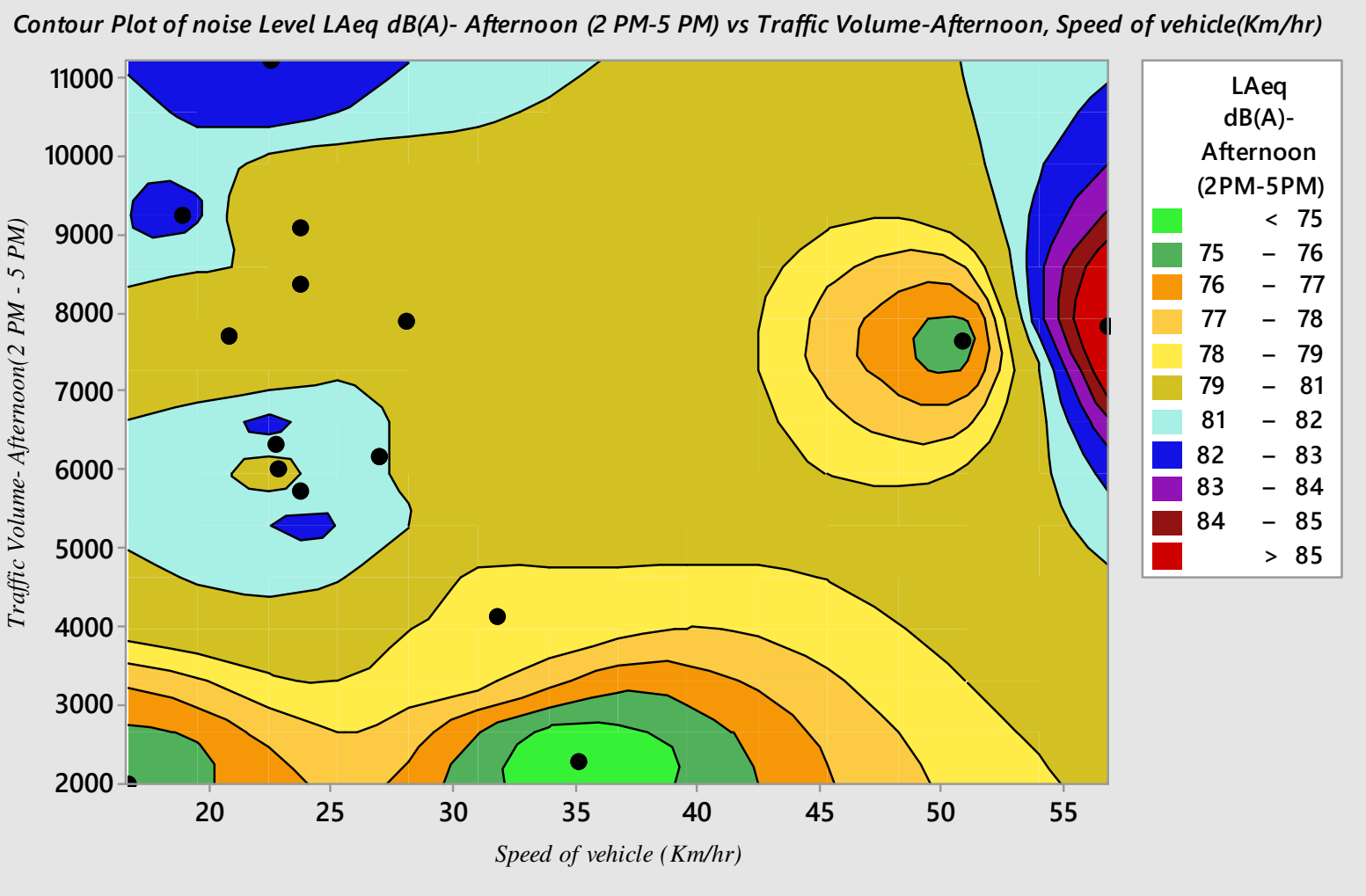

Fig. 5(c) Contour noise plotting of Non-Peak Afternoon Hours (2 PM - 5 PM) w.r.t Traffic Volume \& Speed of vehicles $(\mathrm{Km} / \mathrm{h})$

Fig. 5(c) shows the contour plot of Non-Peak Afternoon Hours (2 PM - 5 PM). This noise segment has less no. of vehicles trespassing the township from 9 AM to 12 PM. At traffic volume 5000-10500 and with velocity between 20$25 \mathrm{Km} / \mathrm{h} \& 55 \mathrm{~km} / \mathrm{h}$ the noise level exceeded $80 \mathrm{~dB}(\mathrm{~A})$ on some monitoring points. At a speed $50 \mathrm{~km} / \mathrm{h}$ and traffic volume around 6000-9000 there is significantly reduce of noise levels due to less no. of vehicles present or less traffic in different city junctions. So, that two wheelers, three wheelers or four wheelers moves easily among city. For the noise level data, the contour plot shows that the highest noise levels were found near an average speed of $55 \mathrm{~km} / \mathrm{h}$ and average traffic volume of around 8000-9000. The lowest noise levels were found in shallow streams regardless of the speed of vehicles at an average traffic volume of 2000-3000. 


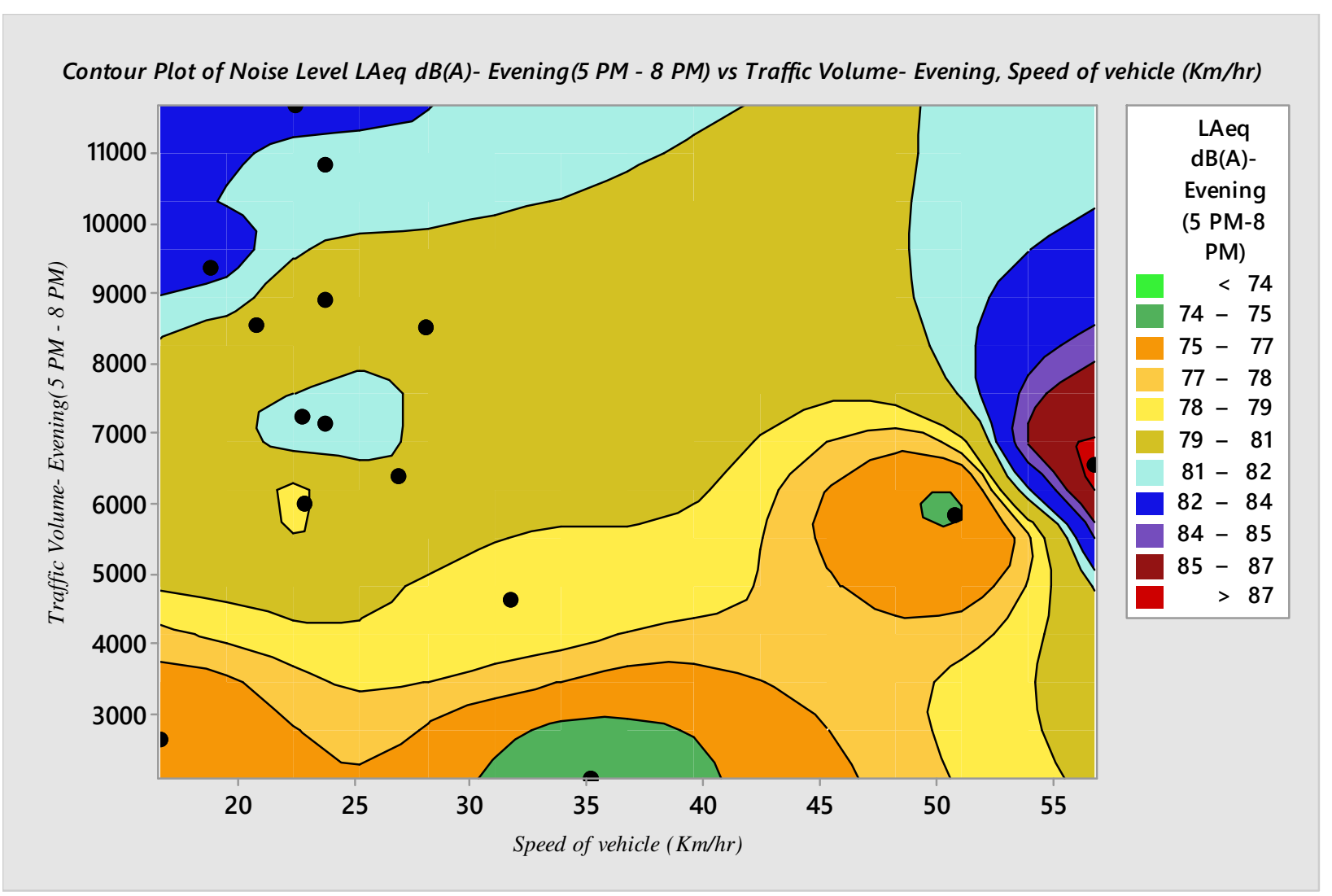

Fig. 5(d) Contour noise plotting of Peak Evening Hours (5 PM - 8 PM) w.r.t Traffic Volume \& Speed of vehicles

$(\mathrm{Km} / \mathrm{h})$

476 Fig. 5(d) shows the contour plot of Peak Evening Hours (5 PM - 8 PM). This noise segment is experiencing noise

477 level in evening hour exceeding $80 \mathrm{~dB}$ (A) regardless of the velocity but at a traffic volume between 6000-11000. The

478 contour plot looks like a flat noise level due to closure of offices, schools, colleges and also day closure of roadside

479 encroachments as vehicles are plying on the road at an idle condition. For the noise level data, the contour plot shows

480 that the highest noise levels [Colour: Red area] were found near an average speed of $55 \mathrm{~km} / \mathrm{h}$ and average traffic

481 volume of around 6000-7000. The lowest noise levels were found in shallow streams regardless of the speed of 482 vehicles at an average traffic volume of less than 3000. 


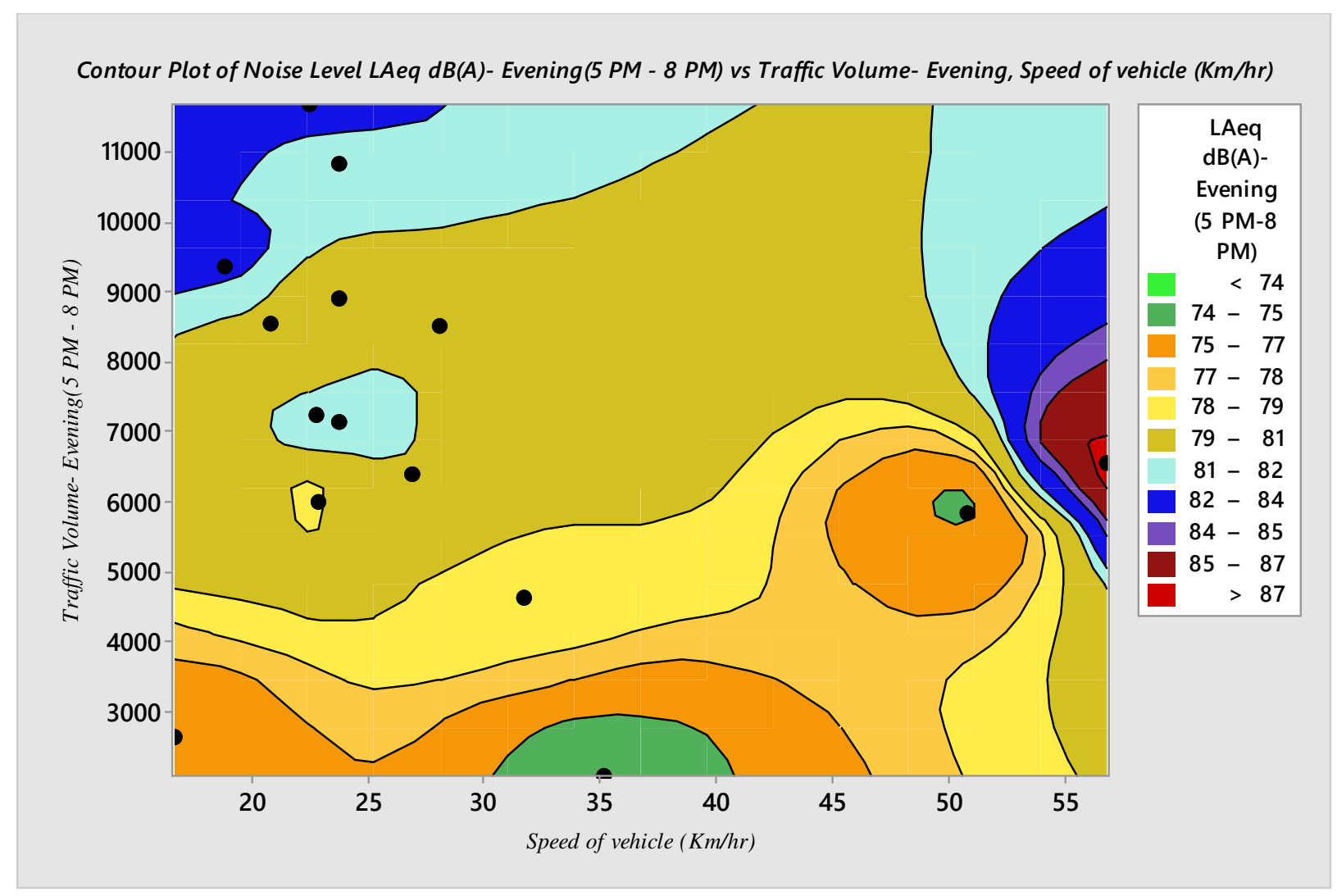

Fig. 5(e) Contour noise plotting of Non-Peak Night Hours (8 PM - 11 PM) w.r.t Traffic Volume \& Speed of vehicles $(\mathrm{Km} / \mathrm{h})$

Fig. 5(e) shows the contour plot of Non- Peak Night Hours (8 PM - 11 PM). As a non-peak hour, this noise segment has among the less no. of vehicles trespassing the township and clearly shows that the speed of vehicles at $30-45 \mathrm{~km} / \mathrm{h}$ has been experiencing lowest no. of traffic volume. At traffic volume 4300-6000 and with velocity less than $25 \mathrm{Km} / \mathrm{h}$ the vehicles noise level is around 76-78 $\mathrm{dB}(\mathrm{A})$ on some monitoring points, they are heavy vehicles plying on the National highways due to traffic jam. In this segment, clearly shows that less no. of vehicles as two wheelers, three wheelers or for wheelers at an extent on the road among other noise hours. For the noise level data, the contour plot shows that the highest noise levels were found near an average speed of $55 \mathrm{~km} / \mathrm{h}$ or more and average traffic volume of around $2500-2900$. The lowest noise levels were found in shallow streams regardless of the speed of vehicles at an average traffic volume of less than 1900 or less.

\subsubsection{ANN Modelling}

This section represents the results of ANN model used in this research. Training, Testing and Validation have been carried out through IBM SPSS 21.0 software package. In the neural analysis Multilayer Perceptron Network have been selected for training purpose. The network information of including input layer, hidden layer and output layer from SPSS 21.0 software package has been shown in Fig. 6. The input parameters are traffic volume, speed of 

adjustment and these have been calculated using equations 6 to 10 of section 3.5 .

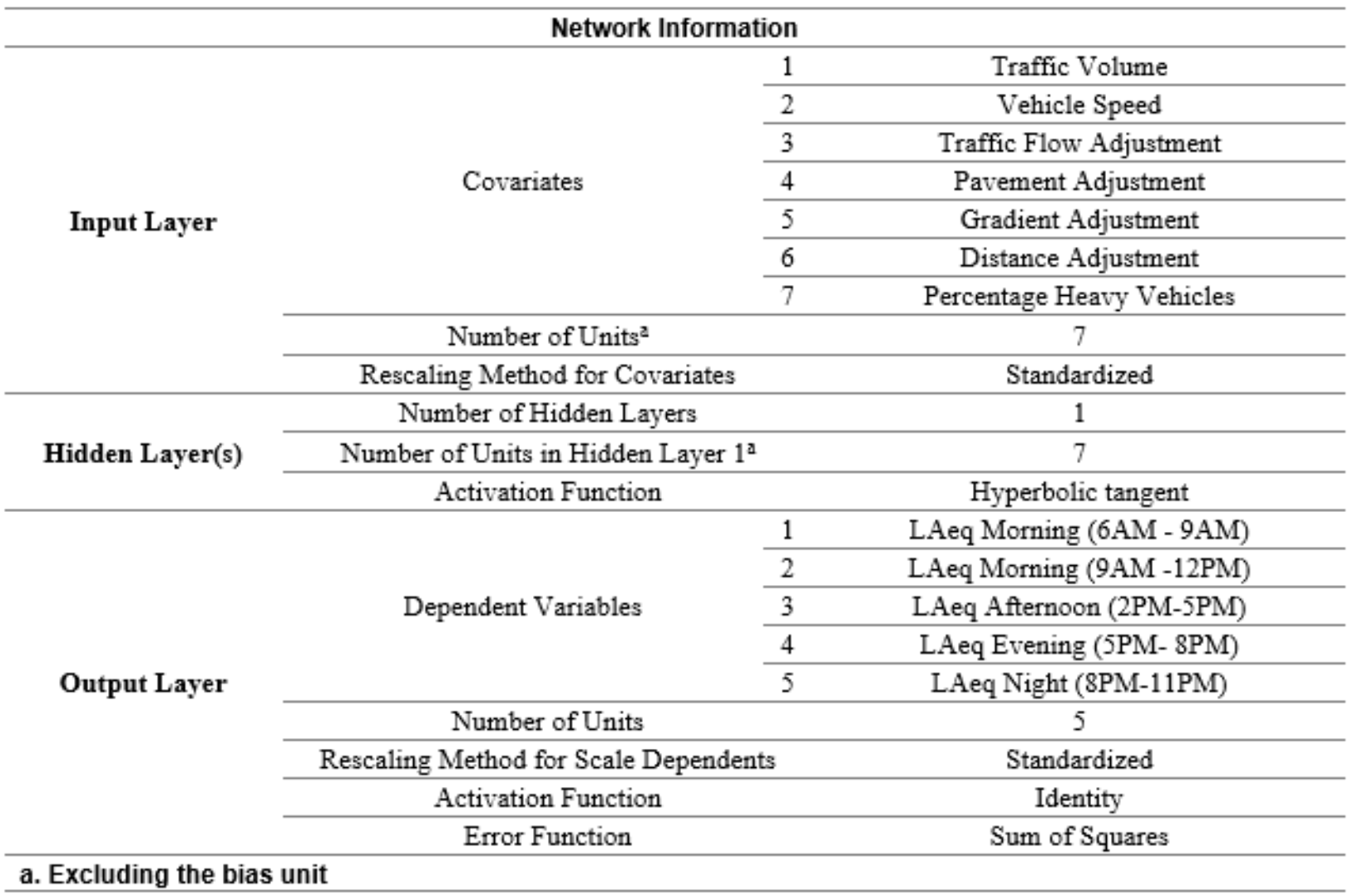

Fig. 6 Neural Network Information (Input, Hidden \& Output layer)

Fig. 7 shows the neural network architecture (7-7-5), with 7 input parameters and 5 output parameters through the 7 units of a hidden layer. Hyperbolic Tangent and Identity act as a activation function of hidden layer and output layer. The thicker lines defines stronger co-relation among the layers. 




Hidden layer activation function: Hyperbolic tangent

Fig. 7 Artificial Neural Network Architecture

Before processing the multi-layer perceptron analysis, the samples have been splitted as training dataset (comprising $86.7 \%$ of the whole dataset) and a testing dataset (comprising $13.3 \%$ of the remaining 15\%). While training dataset were used to determining Artificial Neural Network models and the testing dataset were used to assess the accuracy of the ANN models through the performance of $\mathrm{R}^{2}$ Linear of the predictive charts. 


\begin{tabular}{|c|c|c|c|}
\hline \multicolumn{4}{|c|}{ Model Summary } \\
\hline \multirow{9}{*}{ Training } & & f Squares Error & .858 \\
\hline & & verall Relative Error & .029 \\
\hline & \multirow{5}{*}{$\begin{array}{l}\text { Relative Error for } \\
\text { Scale Dependents }\end{array}$} & LAeq Morning (6AM - 9AM) & .063 \\
\hline & & LAeq Morning (9AM -12PM) & .020 \\
\hline & & LAeq Afternoon (2PM-5PM) & .018 \\
\hline & & LAeq Evening (5PM- 8PM) & .028 \\
\hline & & LAeq Night (8PM-11PM) & .014 \\
\hline & \multicolumn{2}{|c|}{ Stopping Rule Used } & $\begin{array}{c}1 \text { consecutive } \\
\text { step }(s) \text { with no } \\
\text { decrease in error }{ }^{\mathrm{a}}\end{array}$ \\
\hline & & aining Time & $0: 00: 00.02$ \\
\hline \multirow{7}{*}{ Testing } & & f Squares Error & .485 \\
\hline & & verall Relative Error & .862 \\
\hline & \multirow{5}{*}{$\begin{array}{l}\text { Relative Error for } \\
\text { Scale Dependents }\end{array}$} & LAeq Morning (6AM - 9AM) & .655 \\
\hline & & LAeq Morning (9AM -12PM) & 1.918 \\
\hline & & LAeq Afternoon (2PM-5PM) & .239 \\
\hline & & LAeq Evening (5PM- 8PM) & .681 \\
\hline & & LAeq Night (8PM-11PM) & 1.081 \\
\hline
\end{tabular}

\section{a. Error computations are based on the testing sample.}

Fig. 8 Summary of Neural Network Model (Training \& Testing)

Fig. 8 shows summary of neural network model results for training and testing samples. It includes sum of squares error, relative, stopping rule used to stop training, and the training time. The sum of squares error evolves due the activation function as Hyperbolic Tangent applied to the output layer. All the dependent variables measured and input feed to SPSS as a Scale level, due to that average overall relative error or percentage of incorrect predictions has been displayed. Sum of squares error of training and testing sample were 0.858 and 0.458 which is very less for accuracy and there are no holdout samples. Also, the average overall relative error or percentage of incorrect predictions for training samples are .029 and in case of output 0.862 . This error values justifies that model has not overfitted in training samples and testing sample has been prevented overtraining.

Fig. 9 shows parameter estimation of ANN model in input and output layers with respect to 7 units of hidden layer. It summarizes the model-estimated effect of each predictor. The predictive coefficient values for co-variates as input layer and dependent variables as output layer and their signs defines important insights of this network. In case of covariates as input layer, the positive relationships found in traffic volume, vehicle speed, Pavement adjustment, gradient adjustment and inverse relationships found in traffic flow adjustment, distance adjustment, percentage of heavy vehicles. These positive coefficients are contributing extensively for increasing noise level in monitoring stations while inverse coefficients have less impact on the noise level. While in case of dependent variables as output layer, positive relationships found in all noise hours. It reflects all coefficients are positive, indicating all the noise hours contribute to noise level resulting noise pollution. 
532 Hence it is evident from all these above interpretations that, this neural network estimated the predictive coefficients 533 are significant. Table 6 showing the performance comparison of Artificial Neural network predictions with measured 534 noise levels.

535 


\section{Parameter Estimates}

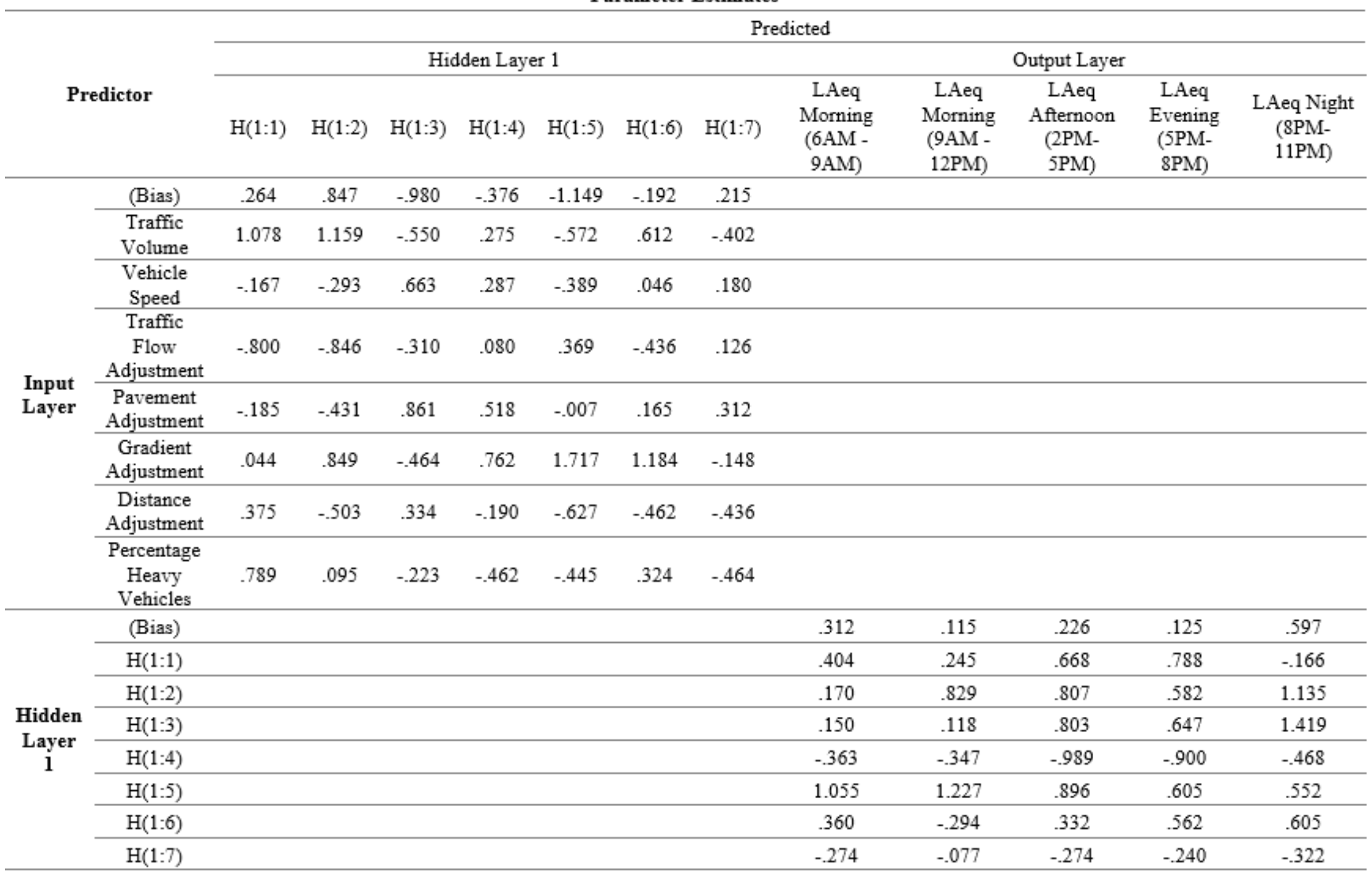

Fig. 9 Predicted Parameter Estimation by Model (Input \& output Layer) 


\begin{tabular}{|c|c|c|c|c|c|c|c|c|c|c|c|c|c|c|c|}
\hline \multirow{2}{*}{\begin{tabular}{|c|} 
Noise Hours \\
Location Name
\end{tabular}} & \multicolumn{3}{|c|}{ Morning (6 AM- 9 AM) } & \multicolumn{3}{|c|}{ Morning (9 AM - 12 PM) } & \multicolumn{3}{|c|}{ Afternoon (2 PM- 5 PM) } & \multicolumn{3}{|c|}{ Evening (5 PM - 8 PM) } & \multicolumn{3}{|c|}{ Night (8 PM - 11 PM) } \\
\hline &  & 芝兽导 & 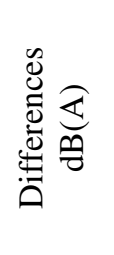 & 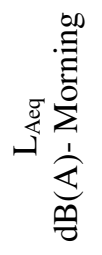 & 芝兽导 & 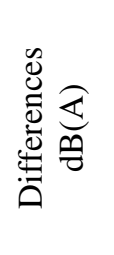 & 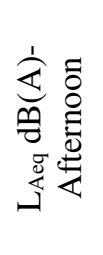 & 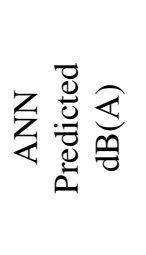 & 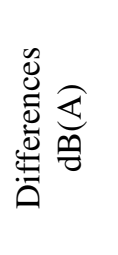 & 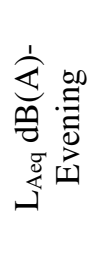 & 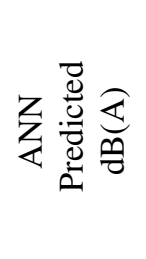 & 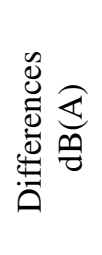 & 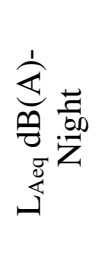 & 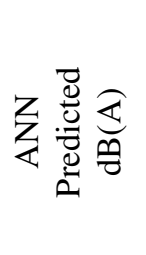 & 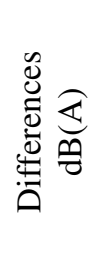 \\
\hline IIT(ISM) Gate & 77.4 & 77.5 & -0.1 & 82.1 & 82.2 & -0.1 & 81.3 & 80.9 & 0.4 & 80.3 & 80.2 & 0.1 & 77.8 & 78.3 & -0.5 \\
\hline $\begin{array}{c}\text { Randhir Verma } \\
\text { Chowk }\end{array}$ & 79.5 & 79.5 & 0.0 & 79.9 & 80.1 & -0.2 & 79.2 & 78.9 & 0.3 & 81.6 & 81.5 & 0.1 & 77.5 & 78.0 & -0.5 \\
\hline City Centre & 79.7 & 79.7 & 0.0 & 80.9 & 81.1 & -0.2 & 80.8 & 80.4 & 0.4 & 80.4 & 80.3 & 0.1 & 76 & 76.5 & -0.5 \\
\hline Steel Gate & 77.2 & 77.3 & -0.1 & 82.9 & 82.9 & 0.0 & 82.7 & 82.3 & 0.4 & 82.1 & 82.0 & 0.1 & 76.4 & 76.9 & -0.5 \\
\hline Memko More & 76.5 & 76.7 & -0.2 & 77.2 & 77.6 & -0.4 & 76 & 75.8 & 0.2 & 75.2 & 75.3 & -0.1 & 72.9 & 73.5 & -0.6 \\
\hline Big Bazaar & 76.7 & 76.9 & -0.2 & 77.6 & 78.0 & -0.4 & 78.7 & 78.4 & 0.3 & 78.3 & 78.3 & 0.0 & 75.8 & 76.3 & -0.5 \\
\hline Kendua Bazaar & 78.7 & 78.7 & 0.0 & 81.4 & 81.5 & -0.1 & 80.8 & 80.4 & 0.4 & 80.7 & 80.6 & 0.1 & 76.8 & 77.3 & -0.5 \\
\hline Bus Stand, Bartand & 83.4 & 83.2 & 0.2 & 84 & 83.9 & 0.1 & 82.4 & 82.0 & 0.4 & 80.8 & 80.7 & 0.1 & 79.5 & 80.0 & -0.5 \\
\hline Govindpur & 85.5 & 85.1 & 0.4 & 86.3 & 86.1 & 0.2 & 86.9 & 86.3 & 0.6 & 87.2 & 86.9 & 0.3 & 82.5 & 82.9 & -0.4 \\
\hline Katras More, Jharia & 79.9 & 79.9 & 0.0 & 82.7 & 82.7 & 0.0 & 80.4 & 80.1 & 0.3 & 78.8 & 78.8 & 0.0 & 77.9 & 78.4 & -0.5 \\
\hline Shramik Chowk & 82.5 & 82.3 & 0.2 & 83.6 & 83.6 & 0.0 & 82.1 & 81.7 & 0.4 & 82.7 & 82.6 & 0.1 & 78.8 & 79.3 & -0.5 \\
\hline Bata More, Jharia & 79.3 & 79.3 & 0.0 & 80.9 & 81.1 & -0.2 & 75.7 & 75.6 & 0.1 & 76.2 & 76.3 & -0.1 & 73.4 & 74.0 & -0.6 \\
\hline $\begin{array}{c}\text { Vinod Vihari } \\
\text { Chowk }\end{array}$ & 76.6 & 76.8 & -0.2 & 77.3 & 77.7 & -0.4 & 74.6 & 74.5 & 0.1 & 74.2 & 74.3 & -0.1 & 71.3 & 71.9 & -0.6 \\
\hline Bank More & 83.4 & 83.2 & 0.2 & 84.2 & 84.1 & 0.1 & 82.8 & 82.4 & 0.4 & 83 & 82.9 & 0.1 & 79.2 & 79.7 & -0.5 \\
\hline Dhansar More & 78.9 & 78.9 & 0.0 & 80.7 & 80.9 & -0.2 & 79.6 & 79.3 & 0.3 & 80.1 & 80.0 & 0.1 & 74.6 & 75.2 & -0.6 \\
\hline
\end{tabular}




\subsubsection{Model Validation}

Developed ANN model and its output parameters have been validated with linear plot against measured noise

543 levels. Five linear plots have been developed to summarize the performance of the model.

544 Fig. 10 shows a predicted by observed value chart for dependent variable $\mathrm{L}_{\mathrm{Aeq}}$ - Morning (6 AM to 9 AM). From Table

5456 , it shows the comparisons between the measured and ANN predicted both noise levels ranges from $-0.2 \mathrm{~dB}(\mathrm{~A})$ to $546+0.4 \mathrm{~dB}(\mathrm{~A})$ with $\mathrm{R}^{2}$ (square of the correlation) value of the line is 0.933 and mean difference were calculated as +0.2 $547 \mathrm{~dB}(\mathrm{~A})$. Except Govindpur station the deviations other stations didn't exceed $0.2 \mathrm{~dB}(\mathrm{~A})$. The mean difference between 548 both predicted and measuring $\mathrm{L}_{\text {Aeq }}$ showed a null difference.

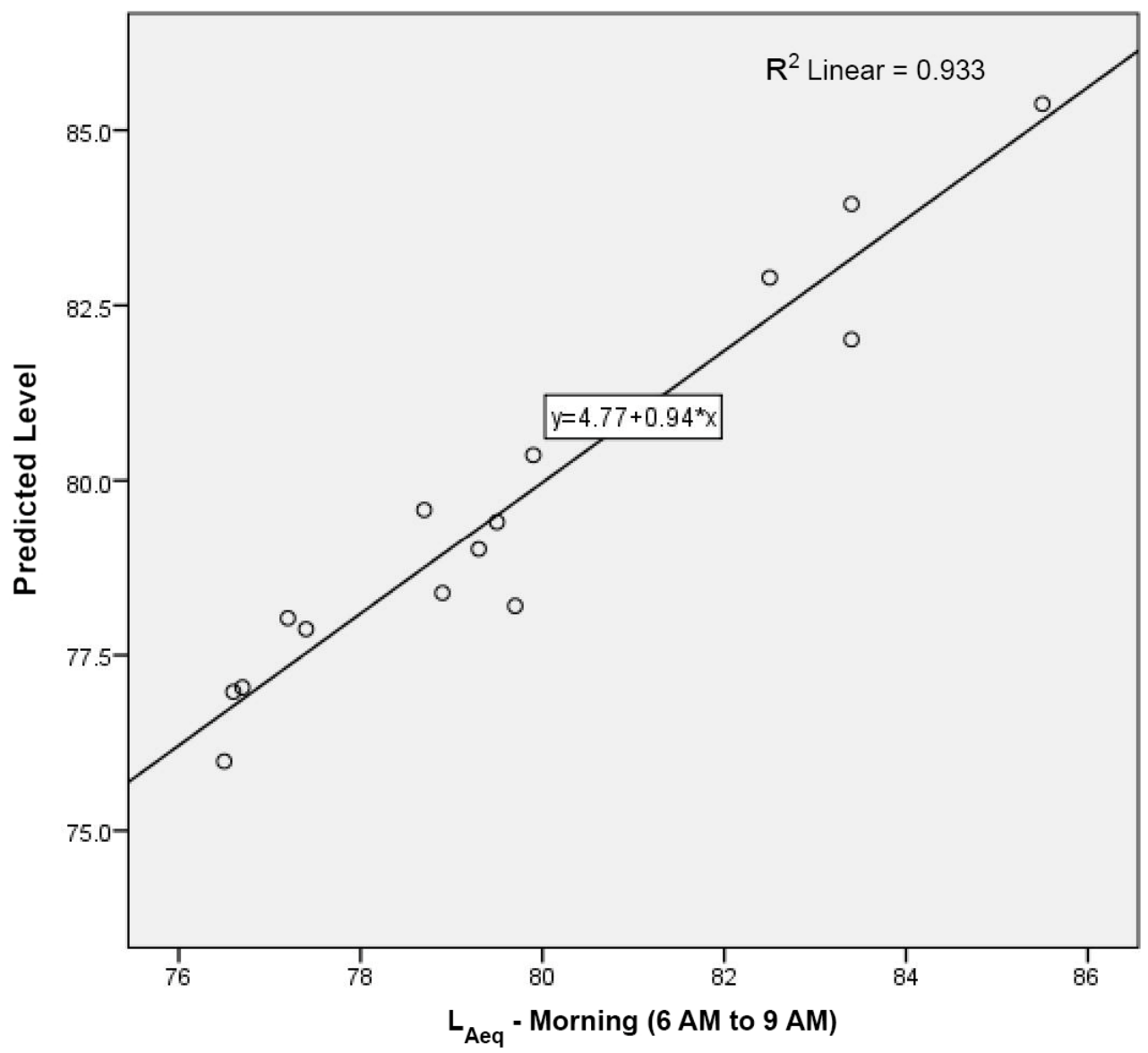

Fig. 10 Predicted by observed value chart for $\mathrm{L}_{\text {Aeq }}$ - Morning (6 AM to 9 AM)

The general form of linear equation developed from observed predicted chart are

$$
L_{\text {Aeq }[6 \text { AM to } 9 \text { AM }(\text { Predicted })]}=4.77+0.94 \times L_{\text {Aeq }[6 \text { AM to } 9 \text { AM (Measured })]}
$$

Fig. 11 shows a predicted by observed value chart for dependent variable $\mathrm{L}_{\text {Aeq }}$ - Morning ( 9 AM to 12 PM). From 

predicted and measuring $\mathrm{L}_{\text {Aeq }}$ showed a difference of $-0.2 \mathrm{~dB}(\mathrm{~A})$.

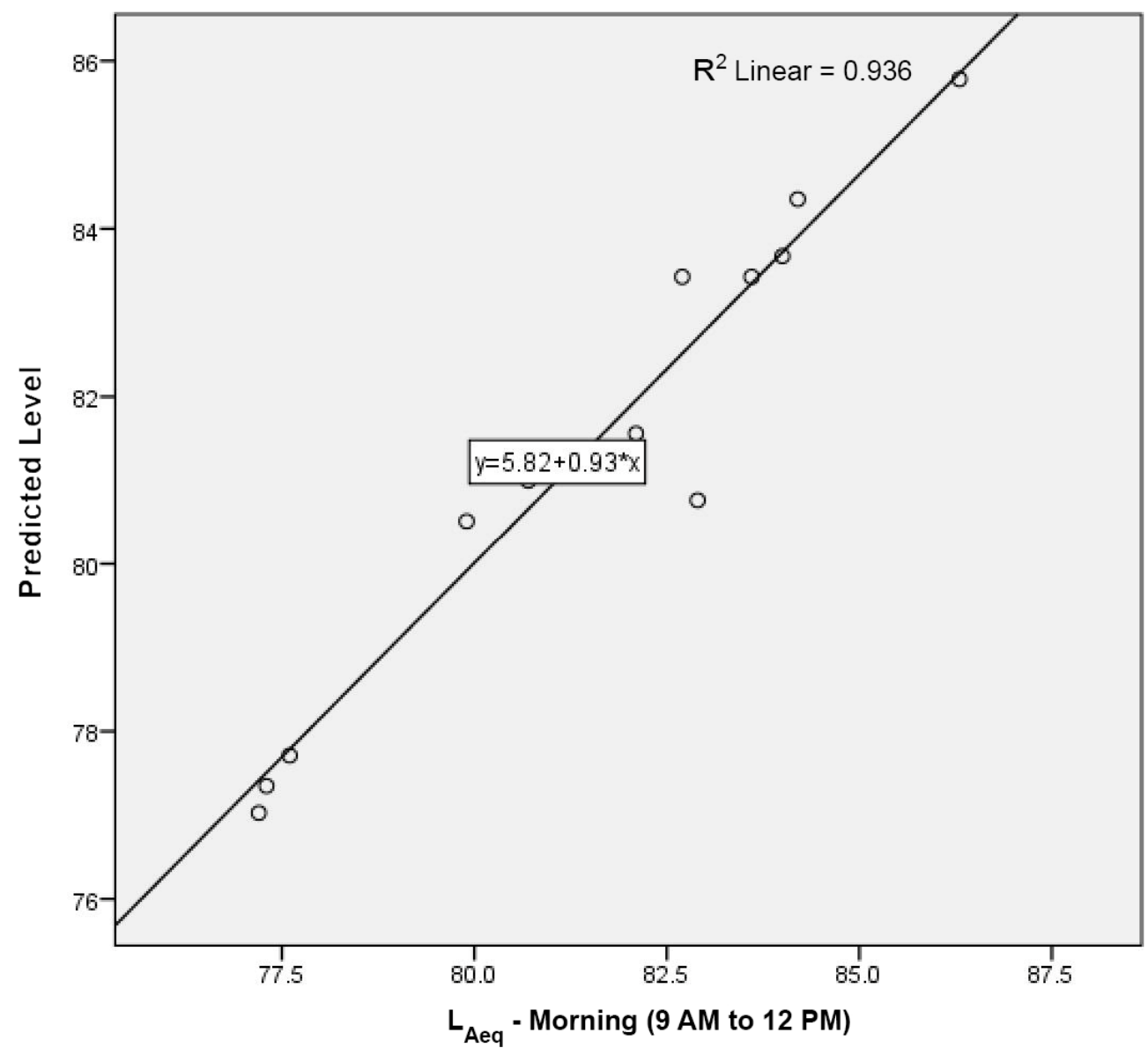

Fig. 11 Predicted by observed value chart for $\mathrm{L}_{\text {Aeq }}$ - Morning (9 AM to $12 \mathrm{PM}$ )

The general form of linear equation developed from observed predicted chart are

$$
L_{\text {Aeq }[9 \text { AM to } 12 \text { PM (Predicted })]}=5.82+0.93 \times L_{\text {Aeq }[9 \text { AM to } 12 \text { PM (Measured })]}
$$

Fig. 12 shows a predicted by observed value chart for dependent variable $\mathrm{L}_{\mathrm{Aeq}}$ - Afternoon (2 PM to 5 PM). From Table 6, it shows the comparisons between the measured and ANN predicted both noise levels ranges from +0.1 $\mathrm{dB}(\mathrm{A})$ to $+0.6 \mathrm{~dB}(\mathrm{~A})$ with $\mathrm{R}^{2}$ (square of the correlation) value of the line is 0.975 and mean difference were calculated as $+0.5 \mathrm{~dB}(\mathrm{~A})$. Except three station the deviations other stations didn't exceed $0.2 \mathrm{~dB}(\mathrm{~A})$. The mean difference between both predicted and measuring $\mathrm{L}_{\mathrm{Aeq}}$ showed a difference of $+0.4 \mathrm{~dB}(\mathrm{~A})$. 


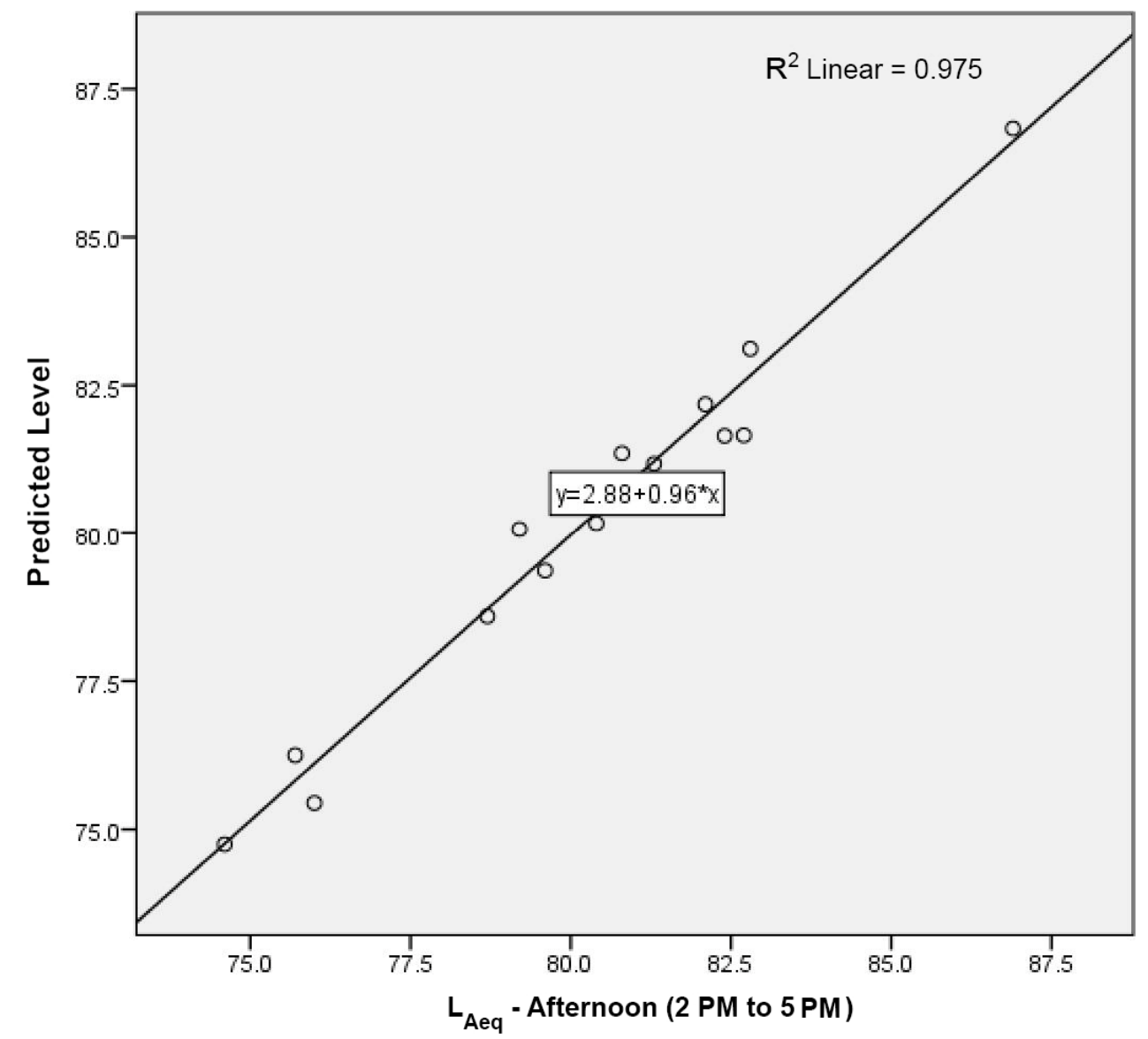

571

Fig. 12 Predicted by observed value chart for $\mathrm{L}_{\text {Aeq }}$ - Afternoon (2 PM to $5 \mathrm{PM}$ )

574 The general form of linear equation developed from observed predicted chart are

$$
L_{\text {Aeq }[2 \text { PM to } 5 \text { PM }(\text { Predicted })]}=2.88+0.96 \times L_{\text {Aeq }[2 \text { PM to } 5 \text { PM (Measured })]}
$$

576 Fig. 13 shows a predicted by observed value chart for dependent variable $\mathrm{L}_{\text {Aeq }}$ - Evening (5 PM to 8 PM). From Table

5776 , it shows the comparisons between the measured and ANN predicted both noise levels ranges from $-0.1 \mathrm{~dB}(\mathrm{~A})$ to

$578+0.3 \mathrm{~dB}(\mathrm{~A})$ with $\mathrm{R}^{2}$ (square of the correlation) value of the line is 0.964 and mean difference were calculated as +0.2

$579 \mathrm{~dB}(\mathrm{~A})$. Except Govindpur station the deviations other stations didn't exceed $0.2 \mathrm{~dB}(\mathrm{~A})$. The mean difference between both predicted and measuring $\mathrm{L}_{\mathrm{Aeq}}$ showed null difference. 


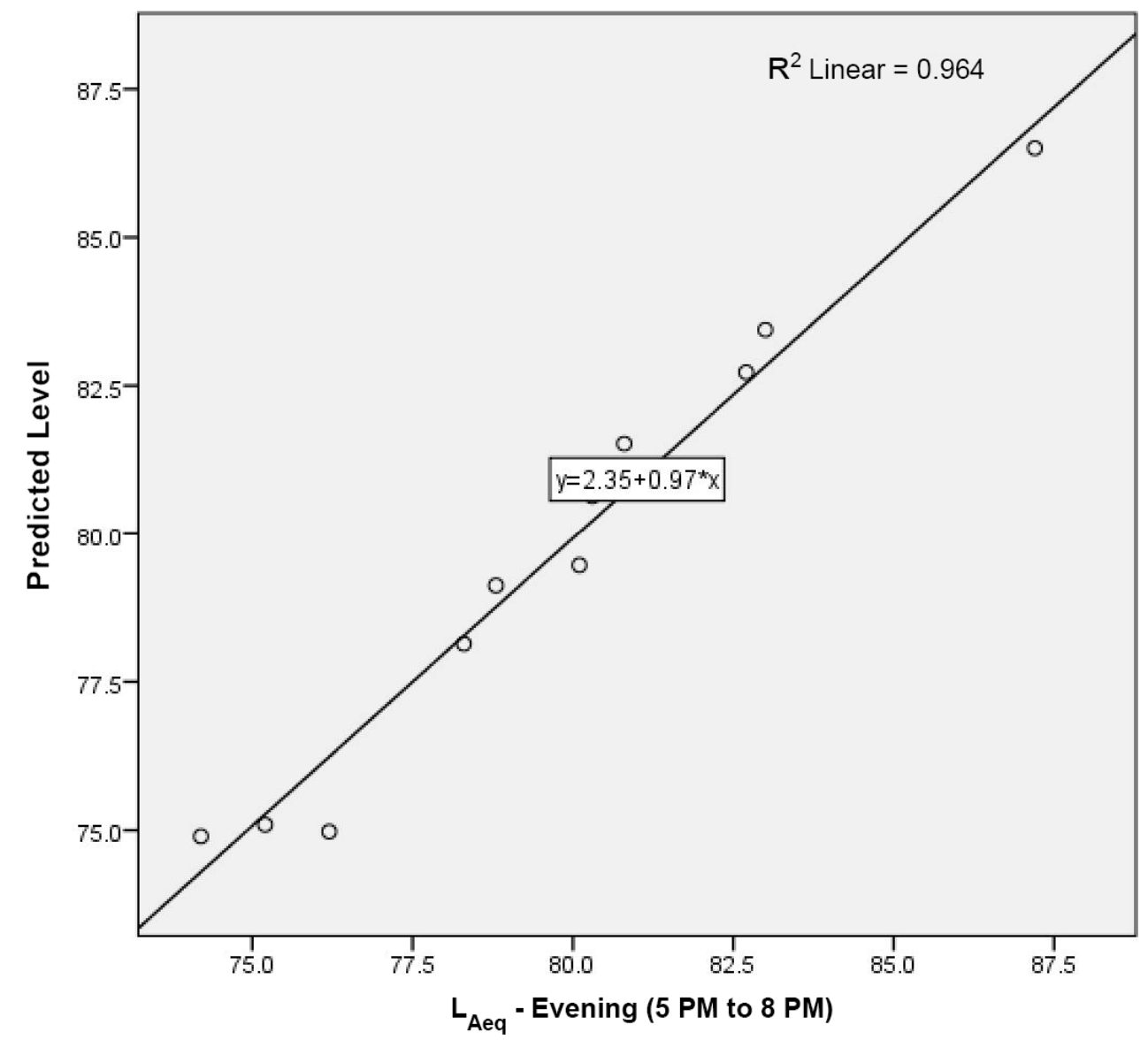

581

Fig. 13 Predicted by observed value chart for $\mathrm{L}_{\mathrm{Aeq}}$ - Evening (5 PM to $8 \mathrm{PM}$ )

The general form of linear equation developed from observed predicted chart are

$$
L_{\text {Aeq }[5 \text { PM to } 8 \text { PM }(\text { Predicted })]}=2.35+0.97 \times L_{\text {Aeq }[5 \text { PM to } 8 \text { PM }(\text { Measured })]}
$$

Fig. 14 shows a predicted by observed value chart for dependent variable $\mathrm{L}_{\text {Aeq }}$ - Night (8 PM to $11 \mathrm{PM}$ ). From Table 6 , it shows the comparisons between the measured and ANN predicted both noise levels ranges from - $0.6 \mathrm{~dB}(\mathrm{~A})$ to $0.5 \mathrm{~dB}(\mathrm{~A})$ with $\mathrm{R}^{2}$ (square of the correlation) value of the line is 0.981 and mean difference were calculated as -0.11 $\mathrm{dB}(\mathrm{A})$. None of the monitoring stations deviations didn't exceed $0.2 \mathrm{~dB}(\mathrm{~A})$. The difference between both predicted and measuring $L_{\text {Aeq }}$ showed a difference of $-0.5 \mathrm{~dB}(\mathrm{~A})$. 


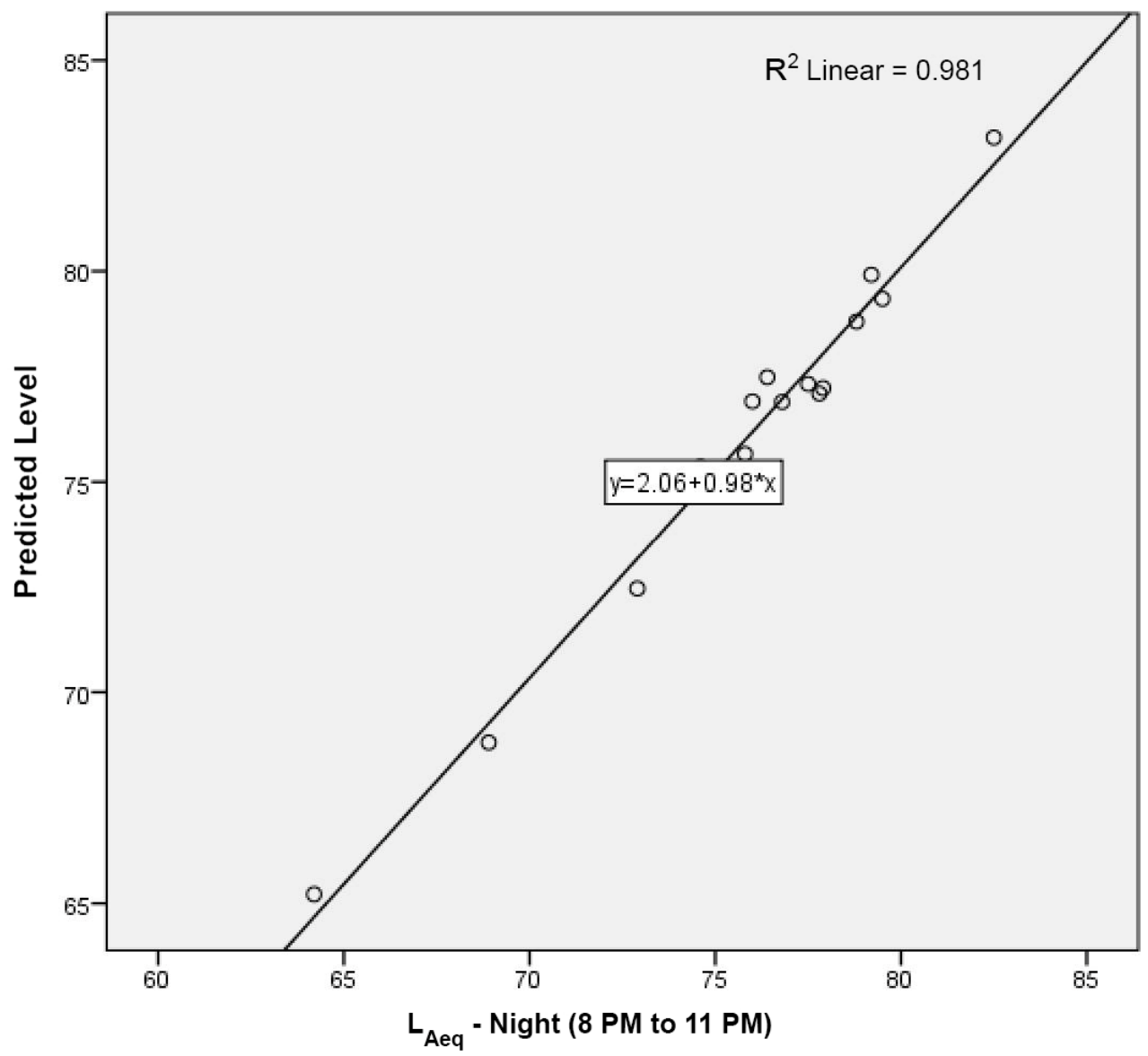

Fig. 14 Predicted by observed value chart for $\mathrm{L}_{\mathrm{Aeq}}$ - Night (8 PM to $\left.11 \mathrm{PM}\right)$

The general form of linear equation developed from observed predicted chart are

$$
L_{\text {Aeq }[8 \text { PM to } 11 \text { PM (Predicted })]}=2.06+0.98 \times L_{\text {Aeq }[8 \text { PM to } 11 \text { PM (Measured })]}
$$

596 It is clearly evident from these five above predicted linear charts against measured values (fig. 10-14) that $\mathrm{R}^{2}$ linear 597 values are well above 0.9 as any value above 0.7 considered good and 1 is the best fit. Also, according to Table 6 598 there's is small variation between measured values with predicted values whereas in case of mean difference Morning (6 AM to 9 AM) and Evening (5 PM to 8 PM) shows a null difference. Therefore, these above plots clearly validate the ANN model.

\subsubsection{Comparisons of modelling according to Goodness of Fit}

602 Table 7 Comparison of predicted noise level predictions between $\mathrm{R}^{2}$ of CRTN based Linear Regression Modelling 603 and Artificial Neural Network Modelling

\begin{tabular}{|c|c|c|}
\hline Predicted Noise Model & Coefficient of determination $\left(\mathrm{R}^{2}\right)$ & References \\
\hline $\begin{array}{c}\text { Artificial neural networks } \\
\text { (Delhi city traffic, India) }\end{array}$ & Predictive parameter $=\mathrm{L}_{\text {Aeq, }} \mathrm{R}^{2}=0.81$; for $\mathrm{L}_{10}, \mathrm{R}^{2}=0.80$ & (Garg et al. 2015) \\
\hline
\end{tabular}




\begin{tabular}{|c|c|c|}
\hline $\begin{array}{c}\text { Open source Traffic Noise } \\
\text { Exposure model } \\
\text { (TRANEX) (Leicester and } \\
\text { Norwich, UK) }\end{array}$ & 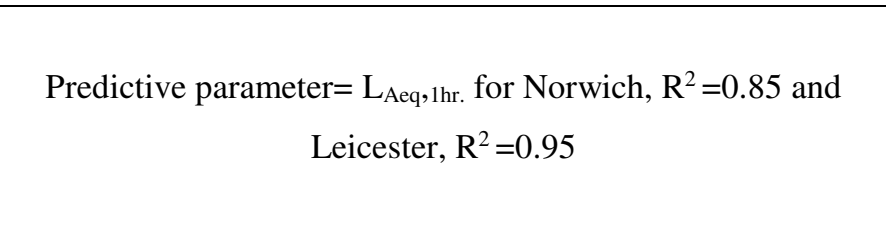 & $\begin{array}{l}\text { (Gulliver et al. } \\
\text { 2015) }\end{array}$ \\
\hline $\begin{array}{l}\text { Neural Networks (Patiala } \\
\text { city traffic, Punjab, India) }\end{array}$ & Predictive parameter $=$ Leq, $R^{2}=0.83$ and for $L_{10}, R^{2}=0.80$ & (Singh et al. 2016) \\
\hline $\begin{array}{l}\text { CRTN based Linear } \\
\text { Regression Modelling } \\
\text { (Dhanbad town road } \\
\text { networks, Jharkhand) }\end{array}$ & $\begin{array}{c}\text { Predictive parameter }=\mathrm{L}_{\text {Aeq. }} \mathrm{R}^{2} \text { Morning }(6 \mathrm{AM}-9 \mathrm{AM})=0.74 \mathrm{R}^{2} \text { Morning } \\
(9 \mathrm{AM}-12 \mathrm{PM})=0.81, \mathrm{R}^{2}{ }_{\text {Afternoon }(2 \mathrm{PM}-5 \mathrm{PM})}=0.71, \mathrm{R}^{2}{ }_{\text {Evening }(5 \mathrm{PM}-8 \mathrm{PM})}= \\
0.69, \mathrm{R}_{\text {Night }(8 \mathrm{PM}-11 \mathrm{PM})=0.60}\end{array}$ & $\begin{array}{l}\text { (Debnath and } \\
\text { Singh, 2018) }\end{array}$ \\
\hline $\begin{array}{c}\text { Modified Federal Highway } \\
\text { Administration (FHWA) } \\
\text { model (Nagpur City road } \\
\text { traffic, India) }\end{array}$ & $\begin{array}{c}\text { Predictive parameter }=\text { Leq, } \mathrm{R}^{2}=0.457 \text { for morning and } \\
\text { evening peak hours }\end{array}$ & $\begin{array}{l}\text { (Pathak et al. } \\
\text { 2018) }\end{array}$ \\
\hline $\begin{array}{c}\text { Traffic noise evaluation } \\
\text { model (TNEM) (Nanguan } \\
\text { District, China) }\end{array}$ & Predictive parameter $=L_{A}$ (instantaneous sound level), $R^{2}=0.86$ & (Di et al. 2018) \\
\hline $\begin{array}{c}\text { Emotional Artificial } \\
\text { Neural Network (EANN) } \\
\text { (Nicosia, North Cyprus) }\end{array}$ & Predictive parameter $=$ Leq, $\mathrm{R}^{2}=0.80$ & $\begin{array}{l}\text { (Nourani et al. } \\
\text { 2020) }\end{array}$ \\
\hline $\begin{array}{l}\text { Artificial Neural Network } \\
\text { (Chongqing city, China) }\end{array}$ & Predictive parameter $=$ Leq, $\mathrm{R}^{2}=0.827$ & (Chen et al. 2020) \\
\hline $\begin{array}{l}\text { Artificial Neural Network } \\
\text { Modelling (Dhanbad town, } \\
\text { India) }\end{array}$ & $\begin{array}{l}\text { Predictive parameter }=\mathrm{L}_{\text {Aeq.. }} \mathrm{R}^{2} \text { Morning }(6 \mathrm{AM}-9 \mathrm{AM})=0.933 \mathrm{R}^{2} \text { Morning } \\
\begin{array}{r}(9 \mathrm{AM}-12 \mathrm{PM})=0.936, \mathrm{R}^{2}{ }_{\text {Afternoon }(2 \mathrm{PM}-5 \mathrm{PM})}=0.975, \mathrm{R}^{2}{ }_{\text {Evening }(5 \mathrm{PM}-8 \mathrm{PM})} \\
=0.964, \mathrm{R}^{2}{ }_{\text {Night }(8 \mathrm{PM}-1 \mathrm{PM})}=0.981\end{array}\end{array}$ & Present study \\
\hline
\end{tabular}

Table 7 compares findings from the current study to prior studies conducted in the domain of traffic noise prediction modelling and its efficacy in various Indian and foreign cities. viz. Artificial Neural Network modelling (Garg et al. 2015; Singh et al. 2016; Chen et al. 2020), Open source Traffic Noise Exposure model (TRANEX) (Gulliver et al.

608 2015), CRTN based Linear Regression modelling (Debnath and Singh, 2018), Modified FHWA modelling (Pathak et 609 al. 2018), Traffic noise evaluation model (TNEM) (Di et al. 2018), Emotional Artificial Neural Network (EANN) 610 (Nourani et al. 2020). It is clearly shown that the $\mathrm{R}^{2}$ value of current Artificial Neural Network based modelling is nearby best fit. There is huge difference among all the noise hours with CRTN based linear regression, modified 612 FHWA modelling. There is also a substantial difference between the current study $\left(\mathrm{R}^{2}\right.$ values more than 0.93 in all 613 times of the day) and prior neural network modelling studies ( $\mathrm{R}^{2}$ values less than or nearby 0.85 ). It is mainly due to 614 the suitability and feed forward architecture of neural network design (with 7 input parameters), as well as hidden 615 layer which acts activation function of weighted input layers. Also, the sum of squares error values are found very less 

suggests that there is less difference up to $\pm 0.6 \mathrm{~dB}(\mathrm{~A})$, which also validates the proposed ANN model.

From the above result of radial noise diagrams it is clearly visible that except some maximum station has exceeded the permissible limit of ambient noise standards for industrial, commercial, residential and silence area has been notified under The Noise Pollution (Regulation and Control) Rules, 2000 (Ministry of Environment and Forests 2000) by Ministry of Environment \& Forest, Govt. of India which is discussed in the literature section. Contour plotting shows the relationship between vehicle speed and traffic volume to act as a driving factor for increasing or decreasing noise levels. The values of different noise descriptors shows the annoyance and disturbing effects, and noise level during 10\% \& 90\% exceeded of time. Also as discussed, the rationale behind using this ANN modelling in literature section and comparisons with regression modelling shows that the performance of this model complies with the existing literatures and their findings.

\subsection{Conclusions}

This study finds suitability of artificial neural network model in Dhanbad township for road traffic noise modelling and it has successfully predicted $\mathrm{L}_{\text {Aeq }}$ noise levels. This present study highlights the vehicular road traffic situation of Dhanbad township by analyzing average noise level based radial figures, noise descriptors and indexes ( $\mathrm{L}_{10}, \mathrm{~L}_{90}, 24 \mathrm{hrs} \mathrm{L}_{\mathrm{dn}}$, LNP, TNI NC) and contour plots (noise level against traffic volume and speed). Following Some conclusions have been drawn from this study-

1. In this paper, we found that the average noise levels of all the stations beyond permissible limit given by under The Noise Pollution (Regulation and Control) Rules, 2000 of Environment (Protection) Act in both peak and non-peak hours. It can be observed that levels were slightly improved during afternoon and night hours.

2. From traffic flow characterization it's clear that that flow are heterogenous where more than $59 \%$ vehicles were two-wheelers, following by $19.37 \%$ four-wheelers, $1.22 \%$ buses \& trekkers, and morning hours (9 AM to 12 PM) has the highest \& night hour has the lowest flow of vehicles recorded all over the Dhanbad township.

3. In case of noise descriptors, Govindpur has highest levels of $\mathrm{L}_{10}$, $\mathrm{L}_{90}$ among the others. It is evident that from observed values that as the traffic volume increases noise level simultaneously increases, the peak levels increase over the time duration due to honking of vehicles in heavy traffic areas. $\mathrm{L}_{\mathrm{dn}}$ levels of several stations found more than 85 $\mathrm{dB}(\mathrm{A})$. The TNI and LNP values are much higher, ranges between 100-200 $\mathrm{dB}(\mathrm{A})$, even in some points it goes beyond $200 \mathrm{~dB}$ (A) which indicates that high annoyance level, variations in flow in Dhanbad township While NC fluctuation level goes up to $45 \mathrm{~dB}(\mathrm{~A})$.

4. From these contour plots, it has been observed that highest noise levels were found at the speed of $50-55 \mathrm{~km} / \mathrm{h}$ in all peak and non-peak hours. The lowest noise levels were found in the shallow streams of the contour with at an average traffic volume of less than 2000 or less. Also, plot suggests that the noise level crucial at a speed of 20-30 and $45-55 \mathrm{~km} / \mathrm{h}$ in peak and non-peak hours where the level crosses $80 \mathrm{~dB}(\mathrm{~A})$ with an traffic volume between 5000-10000. 
5. In this paper, multilayer perceptron neural network has been applied for prediction of noise level. A network architecture with 7-7-5 formation has been processed with user friendly SPSS 21.0 software package and model found as optimum due to its performance in training and testing phase, less sum of square and \% of incorrect prediction errors. The obtained results from ANN showed that the deviation are up to $\pm 0.6 \mathrm{~dB}(\mathrm{~A})$ compared with the measured noise levels. Furthermore, the comparisons between the outputs of ANN and regression based CRTN modelling (Debnath and Singh, 2018), it is found that the $\mathrm{R}^{2}$ linear values of ANN modelling of all the noise hours are more than 0.9 which is nearby best fit and it could be concluded that ANN shows much better capabilities to predict equivalent noise level based on the traffic flow structure than regression modelling in terms of predictive performance of correlation coefficient.

Following several future recommendations also can be made to reduce road traffic noise and usability of the model.

a) Proper management of heavy vehicles including trucks \& buses and construction of noise barrier's in road intersections which will obstruct the noise level at some extent.

b) For better traffic flow management, it will highly advisable that municipality or Gov. urban bodies should install speed bar banner written up to $35-45 \mathrm{~km} / \mathrm{h}$ Max speed in city areas or road intersections.

c) These contour plots can effective for future scenario prediction by policy and decision makers, town planners, municipality and urban bodies and other private stakeholders for road traffic noise management.

d) Use of low noise road surfaces (asphalt road surfaces) is the viable solution to mitigate the noise emitted from tyre-road interaction.

e) This model can help as a useful tool to integrate acoustical variables for urban planners and engineers in future traffic planning, redesigning traffic patterns, slip-roads, fly-overs as a mitigative measure for noise reduction. It will lead to develop future action plans in terms of reduction.

f) The researchers also recommend future research to include more variables or factors as descriptors and indexes viz. $\mathrm{L}_{10}, \mathrm{~L}_{90}, 24 \mathrm{hrs} \mathrm{L}_{\mathrm{dn}}, \mathrm{LNP}, \mathrm{TNI}, \mathrm{NC}$ in a macroscopic approach to develop more comprehensive network model archiving more significant results.

\subsection{Declarations}

6.1.1 Ethics approval and consent to participate: Not Applicable.

6.1.2 Consent to Publish: Not Applicable.

6.1.3 Availability of data and materials: All data generated or analysed during this study are included in this published article.

6.1.4 Competing interests: The authors declare that they have no known competing interests.

6.1.5 Funding: The authors declare that no financial support received for this work that could have influenced its outcome.

6.1.6 Authors' contributions: Conceptualization, Methodology, Writing - original draft, Formal analysis, Validation have been done by Author 1 (Abhijit Debnath). The work has been supervised by the Author 2 (Prasoon Kumar Singh) and drafted manuscript has been reviewed and edited by Author 3 (Sushmita Banerjee). 
6.1.6 Acknowledgements: The authors are sincerely thankful to Department of Environment Science \& Engineering, Indian Institute of Technology (Indian School of Mines), Dhanbad and for providing facilities, guidance and co-operation carrying out the work.

\subsection{References}

Acoustical Society of Japan (1999) ASJ Prediction model 1998 for road traffic noise: Report from the research committee of Road Traffic Noise in the Acoustical Society of Japan

Agarwal S, Swami BL (2010) Noise Annoyance under Interrupted Traffic Flow Condition for Jaipur City. Int J Appl Sci Eng 7:159-168

Avşar Y, Saral A, Gönüllü MT, et al (2004) Neural network modelling of outdoor noise levels in a pilot area. Turkish J Eng Environ Sci 28:149-155. https://doi.org/10.3906/sag-1204-111

Babisch W, Beule B, Schust M, et al (2005) Traffic noise and risk of myocardial infarction. Epidemiology 16:33-40. https://doi.org/10.1097/01.ede.0000147104.84424.24

Bahadure S, Kotharkar R (2018) Framework for measuring sustainability of neighbourhoods in Nagpur, India. Build Environ 127:86-97. https://doi.org/10.1016/j.buildenv.2017.10.034

Banerjee D, Chakraborty SK, Bhattacharyya S, Gangopadhyay A (2008a) Modeling of road traffic noise in the industrial town of Asansol, India. Transp Res Part D Transp Environ 13:539-541. https://doi.org/10.1016/j.trd.2008.09.008

Banerjee D, Chakraborty SK, Bhattacharyya S, Gangopadhyay A (2008b) Evaluation and analysis of road traffic noise in asansol, West Bengal. J Inst Eng Environ Eng Div 89:9-16

Basner M, McGuire S (2018) WHO Environmental Noise Guidelines for the European Region: A Systematic Review on Environmental Noise and Effects on Sleep. Int $\mathbf{J}$ Environ Res Public Health 15:519. https://doi.org/10.3390/ijerph15030519

Bastián-Monarca NA, Suárez E, Arenas JP (2016) Assessment of methods for simplified traffic noise mapping of small cities: Casework of the city of Valdivia, Chile. Sci Total Environ 550:439-448. https://doi.org/10.1016/j.scitotenv.2016.01.139

Bianco F, Fredianelli L, Lo Castro F, et al (2020) Stabilization of a p-u sensor mounted on a vehicle for measuring the acoustic impedance of road surfaces. Sensors (Switzerland) 20:1-16. https://doi.org/10.3390/s20051239

Boodihal MA, Chethan A, Swamy R, et al (2014) Development of tyre/road noise assessment methodology in India. Case Stud Constr Mater 1:115-124. https://doi.org/10.1016/j.cscm.2014.06.001

Bravo-Moncayo L, Lucio-Naranjo J, Chávez M, et al (2019) A machine learning approach for traffic-noise annoyance assessment. Appl Acoust 156:262-270. https://doi.org/10.1016/j.apacoust.2019.07.010

Brown AL, De Coensel B (2018) A study of the performance of a generalized exceedance algorithm for detecting noise events caused by road traffic. Appl Acoust 138:101-114. https://doi.org/10.1016/j.apacoust.2018.03.031

Cai P, Wang Y, Lu G, et al (2016) A spatiotemporal correlative k-nearest neighbor model for short-term traffic multistep forecasting. Transp Res Part C Emerg Technol. https://doi.org/10.1016/j.trc.2015.11.002 
Cammarata G, Cavalieri S, Fichera A (1995) A neural network architecture for noise prediction. Neural Networks. https://doi.org/10.1016/0893-6080(95)00016-S

Chen L, Tang B, Liu T, et al (2020) Modeling traffic noise in a mountainous city using artificial neural networks and gradient correction. Transp Res Part D Transp Environ 78:102196. https://doi.org/10.1016/j.trd.2019.11.025

Chowdhury AK, Debsarkar A, Chakrabarty S (2012) Analysis of day time traffic noise level : A case study of Kolkata, India. Int J Environ Sci Res 2:114-118

De Coensel B, Brown AL, Tomerini D (2016) A road traffic noise pattern simulation model that includes distributions of vehicle sound power levels. Appl Acoust 111:170-178. https://doi.org/10.1016/j.apacoust.2016.04.010

de León G, Del Pizzo A, Teti L, et al (2020) Evaluation of tyre/road noise and texture interaction on rubberised and conventional pavements using CPX and profiling measurements. Road Mater Pavement Des 21:S91-S102. https://doi.org/10.1080/14680629.2020.1735493

Debnath A, Singh PK (2018) Environmental traffic noise modelling of Dhanbad township area - A mathematical based approach. Appl Acoust 129:161-172. https://doi.org/10.1016/j.apacoust.2017.07.023

Del Pizzo A, Teti L, Moro A, et al (2020) Influence of texture on tyre road noise spectra in rubberized pavements. Appl Acoust 159:107080. https://doi.org/10.1016/j.apacoust.2019.107080

Di H, Liu X, Zhang J, et al (2018) Estimation of the quality of an urban acoustic environment based on traffic noise evaluation models. Appl Acoust 141:115-124. https://doi.org/10.1016/j.apacoust.2018.07.010

Dratva J, Phuleria HC, Foraster M, et al (2012) Transportation noise and blood pressure in a population-based sample of adults. Environ Health Perspect 120:50-55. https://doi.org/10.1289/ehp.1103448

Dzhambov A, Tilov B, Markevych I, Dimitrova D (2017) Residential road traffic noise and general mental health in youth: The role of noise annoyance, neighborhood restorative quality, physical activity, and social cohesion as potential mediators. Environ Int. https://doi.org/10.1016/j.envint.2017.09.009

Erickson LC, Newman RS (2017) Influences of Background Noise on Infants and Children. Curr Dir Psychol Sci 26:451-457. https://doi.org/10.1177/0963721417709087

Estévez-Mauriz L, Forssén J (2018) Dynamic traffic noise assessment tool: A comparative study between a roundabout and a signalised intersection. Appl Acoust 130:71-86. https://doi.org/10.1016/j.apacoust.2017.09.003

FHWA Traffic Noise Model (1998) Technical manual, FHWA-PD-96-010

Garg N, Mangal SK, Saini PK, et al (2015) Comparison of ANN and Analytical Models in Traffic Noise Modeling and Predictions. Acoust Aust 43:179-189. https://doi.org/10.1007/s40857-015-0018-3

Gilani TA, Mir MS (2021a) Association of road traffic noise exposure and prevalence of coronary artery disease: A cross-sectional study in North India. Environ Sci Pollut Res. https://doi.org/10.1007/s11356-021-14582-2

Gilani TA, Mir MS (2021b) A study on the assessment of traffic noise induced annoyance and awareness levels about the potential health effects among residents living around a noise-sensitive area. Environ Sci Pollut Res Int. https://doi.org/10.1007/s11356-021-15208-3

Gilani TA, Mir MS (2021c) Modelling road traffic Noise under heterogeneous traffic conditions using the graphtheoretic approach. Environ Sci Pollut Res. https://doi.org/10.1007/s11356-021-13328-4 
Givargis S, Karimi H (2010) A basic neural traffic noise prediction model for Tehran's roads. J Environ Manage 91:2529-2534. https://doi.org/10.1016/j.jenvman.2010.07.011

Givargis S, Mahmoodi M (2008) Converting the UK calculation of road traffic noise (CORTN) to a model capable of calculating LAeq, $1 \mathrm{~h}$ for the Tehran's roads. Appl Acoust. https://doi.org/10.1016/j.apacoust.2007.08.003

Golmohammadi R, Abbaspour M, Nassiri P, Mahjub H (2009) A compact model for predicting road traffic noise. Iran J Environ Heal Sci Eng 6:181-186

Gulliver J, Morley D, Vienneau D, et al (2015) Development of an open-source road traffic noise model for exposure assessment. Environ Model Softw 74:183-193. https://doi.org/10.1016/j.envsoft.2014.12.022

Habtemichael FG, Cetin M (2016) Short-term traffic flow rate forecasting based on identifying similar traffic patterns. Transp Res Part C Emerg Technol. https://doi.org/10.1016/j.trc.2015.08.017

Hamad K, Ali Khalil M, Shanableh A (2017) Modeling roadway traffic noise in a hot climate using artificial neural networks. Transp Res Part D Transp Environ 53:161-177. https://doi.org/10.1016/j.trd.2017.04.014

Hamed MM, Ai-Masaeid HR, Bani Said ZM (1995) Short-term prediction of traffic volume in urban arterials. J Transp Eng. https://doi.org/10.1061/(ASCE)0733-947X(1995)121:3(249)

Heidemann C, Niemann H, Paprott R, et al (2014) Residential traffic and incidence of type 2 diabetes: The german health interview and examination surveys. Diabet Med. https://doi.org/10.1111/dme.12480

Huang B, Pan Z, Liu Z, et al (2017) Acoustic amenity analysis for high-rise building along urban expressway: Modeling traffic noise vertical propagation using neural networks. Transp Res Part D Transp Environ 53:6377. https://doi.org/10.1016/j.trd.2017.04.001

Jha MK, Kang MW (2009) GIS-Based Model for Highway Noise Analysis. J Infrastruct Syst 15:88-94. https://doi.org/10.1061/(asce)1076-0342(2009)15:2(88)

Kalaiselvi R, Ramachandraiah A (2016) Honking noise corrections for traffic noise prediction models in heterogeneous traffic conditions like India. Appl Acoust 111:25-38. https://doi.org/10.1016/j.apacoust.2016.04.003

Khan V, Biligiri KP (2018) Evolution of tyre/road noise research in India: Investigations using statistical pass-by method and noise trailer. Int $J$ Pavement Res Technol 11:253-264. https://doi.org/10.1016/j.ijprt.2017.09.018

Klæboe R, Engelien E, Steinnes M (2006) Context sensitive noise impact mapping. Appl Acoust 67:620-642. https://doi.org/10.1016/j.apacoust.2005.12.002

Konbattulwar V, Velaga NR, Jain S, Sharmila RB (2016) Development of in-vehicle noise prediction models for Mumbai Metropolitan Region, India. J Traffic Transp Eng (English Ed 3:380-387. https://doi.org/10.1016/j.jtte.2016.04.002

Kumar P, Nigam SP, Kumar N (2014) Vehicular traffic noise modeling using artificial neural network approach. Transp Res Part C Emerg Technol 40:111-122. https://doi.org/10.1016/j.trc.2014.01.006

Laxmi V, Dey J, Kalawapudi K, et al (2019) An innovative approach of urban noise monitoring using cycle in Nagpur, India. Environ Sci Pollut Res 26:36812-36819. https://doi.org/10.1007/s11356-019-06817-0 
Licitra G, Fredianelli L, Petri D, Vigotti MA (2016) Annoyance evaluation due to overall railway noise and vibration in Pisa urban areas. Sci Total Environ 568:1315-1325. https://doi.org/10.1016/j.scitotenv.2015.11.071

Licitra G, Teti L, Cerchiai M, Bianco F (2017) The influence of tyres on the use of the CPX method for evaluating the effectiveness of a noise mitigation action based on low-noise road surfaces. Transp Res Part D Transp Environ 55:217-226. https://doi.org/10.1016/j.trd.2017.07.002

Lv Y, Duan Y, Kang W, et al (2015) Traffic Flow Prediction with Big Data: A Deep Learning Approach. IEEE Trans Intell Transp Syst. https://doi.org/10.1109/TITS.2014.2345663

Manojkumar N, Basha K, Srimuruganandam B (2019) Assessment, Prediction and Mapping of Noise Levels in Vellore City, India. Noise Mapp. https://doi.org/10.1515/noise-2019-0004

Marathe PD (2012) Traffic noise pollution. Ijed 9:63-68

Miedema HME, Oudshoorn CGM (2001) Annoyance from transportation noise: Relationships with exposure metrics DNL and DENL and their confidence intervals. Environ Health Perspect 109:409-416. https://doi.org/10.1289/ehp.01109409

Minichilli F, Gorini F, Ascari E, et al (2018) Annoyance judgment and measurements of environmental noise: A focus on italian secondary schools. Int $\mathrm{J}$ Environ Res Public Health 15:1-17. https://doi.org/10.3390/ijerph15020208

Ministry of Environment and forest (2000) The Noise Pollution (Regulation and Control) Rules, 2000. 12311:10881569

Ministry of Environment and Forests G of I (2000) The Noise Pollution (Regulation and Control) Rules, 2000. 123:

Muzet A (2007) Environmental noise, sleep and health. Sleep Med Rev 11:135-142. https://doi.org/10.1016/j.smrv.2006.09.001

Nedic V, Despotovic D, Cvetanovic S, et al (2014) Comparison of classical statistical methods and artificial neural network in traffic noise prediction. Environ Impact Assess Rev 49:24-30. https://doi.org/10.1016/j.eiar.2014.06.004

Nourani V, Gökçekuş H, Umar IK, Najafi H (2020) An emotional artificial neural network for prediction of vehicular traffic noise. Sci Total Environ 707:. https://doi.org/10.1016/j.scitotenv.2019.136134

Paschalidou AK, Kassomenos P, Chonianaki F, Valkouma T (2019) 3-year noise monitoring and strategic noise mapping in an extended motorway. Environ Sci Pollut Res. https://doi.org/10.1007/s11356-019-04966-w

Pathak SS, Lokhande SK, Kokate PA, Bodhe GL (2018) Assessment and Prediction of Environmental Noise Generated by Road Traffic in Nagpur City, India. In: Singh VP, Yadav S, Yadava RN (eds) Environmental Pollution, Water Science and Technology Library, 77th edn. Springer, Singapore, pp 167-180

Pathak V, Tripathi BD, Mishra V kumar (2008) Evaluation of traffic noise pollution and attitudes of exposed individuals in working place. Atmos Environ 42:3892-3898. https://doi.org/10.1016/j.atmosenv.2007.12.070

Peng J, Parnell J, Kessissoglou N (2019) A six-category heavy vehicle noise emission model in free-flowing condition. Appl Acoust 143:211-221. https://doi.org/10.1016/j.apacoust.2018.08.030 
Petri D, Licitra G, Vigotti MA, Fredianelli L (2021) Effects of Exposure to Road, Railway, Airport and Recreational Noise on Blood Pressure and Hypertension. Int J Environ Res Public Health 18:9145. https://doi.org/10.3390/ijerph18179145

Praticò FG (2014) On the dependence of acoustic performance on pavement characteristics. Transp Res Part D Transp Environ 29:79-87. https://doi.org/10.1016/j.trd.2014.04.004

Praticò FG, Anfosso-Lédée F (2012) Trends and Issues in Mitigating Traffic Noise through Quiet Pavements. In: Procedia - Social and Behavioral Sciences. Elsevier B.V., pp 203-212

Praticò FG, Fedele R, Pellicano G (2021) Monitoring Road Acoustic and Mechanical Performance. In: Rizzo P, Milazzo A (eds) European Workshop on Structural Health Monitoring. EWSHM 2020. Lecture Notes in Civil Engineering, 127th edn. Springer, Cham, pp 594-602

Quartieri J, Mastorakis NE, Iannone G, et al (2009) A Review of Traffic Noise Predictive Noise Models. In: Recent Advances in Applied and Theoretical Mechanics

Ramírez A, Domínguez E (2013) Modeling urban traffic noise with stochastic and deterministic traffic models. Appl Acoust 74:614-621. https://doi.org/10.1016/j.apacoust.2012.08.001

Rossi L, Prato A, Lesina L, Schiavi A (2018) Effects of low-frequency noise on human cognitive performances in laboratory. Build Acoust 25:17-33. https://doi.org/10.1177/1351010X18756800

Sandberg U, Ejsmont JA (2002) Tyre/Road Noise Reference Book. In: Kisa, Sweden; Harg, Sweden : INFORMEX. p 640 p.

Sharma A, Bodhe G, Schimak G (2014) Development of a traffic noise prediction model for an urban environment. Noise Heal 16:63. https://doi.org/10.4103/1463-1741.127858

Singh D, Nigam SP, Agrawal VP, Kumar M (2016) Vehicular traffic noise prediction using soft computing approach. J Environ Manage 183:59-66. https://doi.org/10.1016/j.jenvman.2016.08.053

Steele C (2001) Critical review of some traffic noise prediction models. Appl Acoust. https://doi.org/10.1016/S0003$682 \mathrm{X}(00) 00030-\mathrm{X}$

Steinbach L, Altinsoy ME (2019) Prediction of annoyance evaluations of electric vehicle noise by using artificial neural networks. Appl Acoust 145:149-158. https://doi.org/10.1016/j.apacoust.2018.09.024

Tan H, Wu Y, Shen B, et al (2016) Short-Term Traffic Prediction Based on Dynamic Tensor Completion. IEEE Trans Intell Transp Syst. https://doi.org/10.1109/TITS.2015.2513411

Teti L, de León G, Del Pizzo A, et al (2020) Modelling the acoustic performance of newly laid low-noise pavements. Constr Build Mater 247:118509. https://doi.org/10.1016/j.conbuildmat.2020.118509

Thakre C, Laxmi V, Vijay R, et al (2020) Traffic noise prediction model of an Indian road: an increased scenario of vehicles and honking. Environ Sci Pollut Res. https://doi.org/10.1007/s11356-020-09923-6

Vijay R, Chakrabarti T, Gupta R (2018) Characterization of Traffic Noise and Honking Assessment of an Indian Urban Road. Fluct Noise Lett. https://doi.org/10.1142/S0219477518500311

Vukić L, Mihanović V, Fredianelli L, Plazibat V (2021) Seafarers' perception and attitudes towards noise emission on board ships. Int J Environ Res Public Health 18:. https://doi.org/10.3390/ijerph18126671 
864 Wang J, Deng W, Guo Y (2014) New Bayesian combination method for short-term traffic flow forecasting. Transp Res Part C Emerg Technol. https://doi.org/10.1016/j.trc.2014.02.005

866 Wunderli JM, Pieren R, Habermacher M, et al (2016) Intermittency ratio: A metric reflecting short-term temporal

867 variations of transportation noise exposure. J Expo Sci Environ Epidemiol 26:575-585.

868 https://doi.org/10.1038/jes.2015.56

869 Zacarías FF, Molina RH, Ancela JLC, et al (2013) Noise exposure in preterm infants treated with respiratory support

870 using neonatal helmets. Acta Acust united with Acust 99:590-597. https://doi.org/10.3813/AAA.918638

871 Zannin PHT, Engel MS, Fiedler PEK, Bunn F (2013) Characterization of environmental noise based on noise 872 measurements, noise mapping and interviews: A case study at a university campus in Brazil. Cities 31:317327. https://doi.org/10.1016/j.cities.2012.09.008 